Manuscript for: Separation and Purification Technology

\title{
Non-equilibrium solvent extraction in milliflow reactors: precious and base metal separations with undiluted ionic liquids
}

Willem Vereycken ${ }^{\dagger}$, Joren van Stee ${ }^{\ddagger}$, Sofía Riaño ${ }^{\dagger}$, Tom Van Gerven ${ }^{\ddagger}$, Koen Binnemans ${ }^{*}{ }^{\dagger}$

${ }^{\dagger}$ KU Leuven, Department of Chemistry, Celestijnenlaan 200F, P.O. box 2404, B-3001

Leuven, Belgium.

${ }^{\ddagger}$ KU Leuven, Department of Chemical Engineering, Celestijnenlaan 200F, P.O. box 2424, B3001 Leuven, Belgium.

W. Vereycken, J. van Stee, S. Riaño, T. Van Gerven, K. Binnemans

Separation and Purification Technology 265 (2021) 118490 (13 pages).

DOI: 10.1016/j.seppur.2021.118490

*Corresponding author:

Email: Koen.Binnemans@kuleuven.be 


\section{Abstract}

Milliflow devices operating under slug flow (Taylor-flow) conditions provide an efficient mass transfer, a highly uniform droplet morphology and a narrow residence time distribution i.e. characteristics which are excellent for the performance of reactions under kinetic control. Milliflow devices have also been proposed in combination with ionic liquids, due to their ability to intensify the solvent use of these rather expensive and viscous liquids. In present research, the solvent extraction separation of a mixture of $\mathrm{Au}(\mathrm{III}), \mathrm{Pd}(\mathrm{II}), \mathrm{Cu}(\mathrm{II})$ and $\mathrm{Fe}(\mathrm{III})$ was studied using the chloride and bromide forms of the undiluted quaternary ammonium ionic liquid Aliquat 336 in a slug flow reactor channel with an internal diameter of $1.0 \mathrm{~mm}$. The extraction of $\mathrm{Au}(\mathrm{III})$ and $\mathrm{Pd}(\mathrm{II})$ was found to be faster than that of $\mathrm{Cu}(\mathrm{II})$ and $\mathrm{Fe}(\mathrm{III})$, allowing the precious/base metal separation to be improved by modification of the contact time between both phases. An apparent correlation between the observed extraction rates and the equilibrium distribution ratio $D$ was found. The most significant separation improvement was achieved at those conditions where the equilibrium separation was best i.e. low halide and metal concentrations and low organic-to-aqueous flow rate ratios. At a residence time of $25 \mathrm{~s}$, quantitative $\mathrm{Au}(\mathrm{III})$ and $\mathrm{Pd}(\mathrm{II})$ recovery was achieved and decontamination factors increased by a factor up to 2, which corresponds to an increase in product purity of up to $14 \%$. Upon substituting the chloride system for a bromide extraction medium, similar observations were made, except for a reversed $\mathrm{Cu}(\mathrm{II}) / \mathrm{Fe}(\mathrm{III})$ selectivity. Experiments were also conducted on the separation of $\mathrm{Pt}(\mathrm{IV}), \mathrm{Pd}(\mathrm{II})$ and $\mathrm{Rh}(\mathrm{III})$, where a reduced $\mathrm{Rh}(\mathrm{III})$ extraction rate was observed, allowing to suppress its co-extraction by up to $20 \%$. A hydrodynamic analysis of the obtained flow regime of the ionic liquids revealed a stable and uniform slug flow characterized by a decreasing plug length and width with increasing flow rates. A comparison of the applied and observed phase ratio revealed a stagnant ionic liquid excess (i.e. hold-up) inside the reactor of up to $40 \%$ which effectively reduced the reactor diameter and consequently plug residence time. 


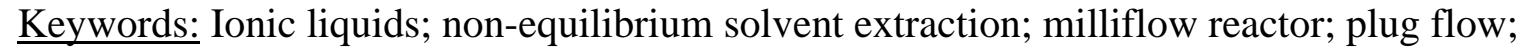
precious metals. 


\section{Introduction}

Solvent extraction (SX) is a popular technique used for metal separation and purification. The technique is based on differences in the distribution of the respective metals between two immiscible liquid phases. Metals are extracted from an aqueous phase to an organic phase containing the extractant (i.e. the solvent).[1] Typically, the process is operated at or very close to chemical equilibrium.[2] Hence, the metals are separated based on their thermodynamic affinity for the solvent. However, it is also possible to perform extractions at non-equilibrium conditions and to exploit differences in the extraction rate to achieve (improved) metal separations which might be unfavorable from a thermodynamic point of view. Differences in extraction rate can usually be related to differences in the lability of metal complexes towards substitution, differences in interfacial rate determining reactions or differences in steric hindrance during complexation with the extractant.[3-5] This kinetic rather than thermodynamic process control has been studied for several metal separations: e.g. $\mathrm{Cu}(\mathrm{II}) / \mathrm{Fe}(\mathrm{III})$ using Kelex-100,[6] Ni(II)/Co(III) using a phosphate extractant,[7] Ni(II)/Co(II) using a synergic SX system comprised of LIX 63 and Versatic Acid 10,[8] In(III)/Fe(III) with D2EHPA,[9,10] rare-earth elements (REE) using diethylenetriaminepentaacetic acid (DTPA) as complexing agent in the aqueous phase and Cyanex 272, D2EHPA or Aliquat 336 nitrate extractants,[11-14] REE/Fe(III) with Cyanex 923 or D2EHPA,[15-17] and platinum-group metals through the use of anions such as $\mathrm{SCN}^{-}$or neutral ligands (often sulphur-containing).[4]

A suitable phase contactor for non-equilibrium SX methods should enable thorough mixing, rapid phase separation, low solvent volume, short contact times and a narrow residence time distribution (RTD). Conventional continuous stirred tank contactors (i.e. mixer-settlers) or extraction columns are inadequate as they are usually characterized by a large solvent volume, rather long contact times and RTDs with significant tailing.[18,19] Centrifugal contactors have been used in a number of studies as they allow for short contact times, while providing good 
mixing and rapid phase separation.[10,15-17,20] A technology that has been gaining interest in recent years, mainly in the field of process intensification, is that of milli- or microfluidic devices (millimeter or micrometer sized reaction channels, respectively). The use of small-scale flow contactors provides several advantages for two-phase liquid-liquid systems, such as increased mass and heat transfer rates, large specific interfacial areas, reduced energy consumption and small solvent volume.[21] As such, this technology has been used in numerous solvent extraction studies on metal extractions and separations.[22-26] A popular flow pattern is slug flow (also referred to as plug flow or Taylor flow) where the immiscible phases form a segmented flow of sequential slugs and plugs. Internal vortices are formed inside the plugs due to a shear exerted by the continuous phase on the surface of the plug, leading to a very efficient mass transfer.[27-29] In addition, slug flow offers a uniform droplet morphology and a narrow RTD, which approaches that of an ideal plug flow reactor. Such conditions are excellent for performing reactions under kinetic control or the study of kinetics.[29-34] The slugs can be seen as identical, small-scale batch reactors with a highly uniform and precise residence time defined by the channel dimensions and the applied flow rate. Since no fine dispersion is created, gravitational settling of the mixture is usually rapid.[35] Some inline phase separation systems have also been developed based on differences in wettability of a side-channel, membrane or mesh.[36-40] By providing an intense phase contacting and high residence time control, small-scale flow contactors operating under slug flow conditions meet the requirements for a reliable operation of non-equilibrium SX processes. In contrast with centrifugal contactors, these flow devices can be highly modular and flexible, small and lightweight and can be constructed with commercially available low-cost tubing and joints made from chemically resistant high-performance polymers.[41] Flow contactors are well suited for laboratory research and low-volume applications on non-equilibrium SX. Due to scale-up difficulties, centrifugal contactors should be considered for large-volume non- 
equilibrium applications.[42] Some reports on the non-equilibrium enhancement of metal separations under slug flow conditions are available in the literature. Yin et al. achieved an increased $\operatorname{Pr}(\mathrm{III}) / \mathrm{Ce}(\mathrm{III})$ separation factor at short contact times in slug flow compared to batch experiments based on differences in extraction rate using 2-ethylhexyl phosphonic acid mono(2-ethylhexyl) ester.[43] Zhang et al. observed a similar trend for the Co(II)/Ni(II) separation using Cyanex 272.[44] Hirayama et al. achieved an increased selectivity and product purity at short contact times for the Co(II)/Li(I) separation using partially saponified D2EHPA.[45]

A technology which has been increasingly suggested in combination with milli- or microfluidics is that of ionic liquids (ILs).[32,46,47] ILs are solvents consisting solely out of ions and are characterized by a wide liquidus range, intrinsic electrical conductivity, nonvolatility and non-flammability. However, there are also several drawbacks to the use of undiluted ILs, mainly their relatively high cost, high viscosity and reduced mass transfer rates which limit their economic applicability. These drawbacks can be well resolved in combination with small-scale flow contactors.[48] ILs have been the subject of numerous studies and have shown great potential in various applications.[49] Of particular interest in combination with milli- or microfluidic devices are multiphase mass transfer processes such as solvent extractions. ILs have shown excellent selectivity and efficiency in various solvent extraction studies for metal separation applications.[50-52]

In this work, non-equilibrium metal separations in a milliflow set-up operating in the slug flow regime have been studied using the commercially available ionic liquid Aliquat 336, a mixture of different quaternary ammonium chlorides, with trioctylmethylammonium chloride as the main component. Both the original chloride form [A336][Cl] and the corresponding bromide form [A336][Br] have been considered. In line with previous work, experiments have been performed using undiluted ionic liquids and chloride and bromide feed solutions.[53] To the best of our knowledge, this is the first report of the use of the undiluted ionic liquid Aliquat 336 
in a milli- or microfluidic contactor. The research involves a study of different parameters influencing the non-equilibrium metal separations. The obtained slug flow has been analyzed with high-speed imaging and several hydrodynamic parameters have been evaluated. Experiments have been performed on the separation of $\mathrm{Au}(\mathrm{III})$ and $\mathrm{Pd}(\mathrm{II})$ from $\mathrm{Cu}(\mathrm{II})$ and Fe(III) and the separation of Pt(IV) and Pd(II) from Rh(III). These case studies have been selected because of the presence of critical raw materials for the EU and their relevance to the recycling industry i.e. waste electric and electronic equipment and car exhaust catalysts. Moreover, the high value of precious metals justifies the use of ionic liquids. The performed research aims to present slug flow contactors for the execution of non-equilibrium SX processes and to give the proof-of-principle that highly viscous, undiluted ionic liquids can be used for solvent extraction in such reactors. 


\section{Experimental}

\subsection{Chemicals}

Aliquat ${ }^{\circledR} 336, \mathrm{HBr}(48 \mathrm{wt} \%), \mathrm{NaAuCl}_{4} \cdot 2 \mathrm{H}_{2} \mathrm{O}$ (99.99\%), $\mathrm{NaAuBr}_{4} \cdot 2 \mathrm{H}_{2} \mathrm{O}$ (99.99\%) and $\mathrm{FeBr} 3$ (>98\%) were purchased from Thermo Fisher Scientific (Merelbeke, Belgium). $\mathrm{NaCl}$ (>99\%), $\mathrm{NaBr}(\geq 99.5 \%), \mathrm{PdBr}_{2}$ (39.8-40.1 wt\% Pd), $\mathrm{RhCl}_{3}$ (38 wt\% Rh), $\mathrm{H}_{2} \mathrm{PtCl}_{6} \cdot 6 \mathrm{H}_{2} \mathrm{O}$ (99.9\%) and $\mathrm{CuCl}_{2}$ (99\%) were acquired from Acros Organics (Geel, Belgium). L-cysteine (97\%) and the gold standard (1000 mg L ${ }^{-1}$ in 5 wt\% $\mathrm{HCl}$ ) were obtained from Sigma-Aldrich (Overijse, Belgium). $\mathrm{HNO}_{3}$ (65 wt\%), the iron, gallium, copper and yttrium standard solutions (1000 mg $\mathrm{L}^{-1}$ in $\left.2-5 \mathrm{wt} \% \mathrm{HNO}_{3}\right)$ and palladium, platinum and rhodium standard solutions (1000 $\mathrm{mg} \mathrm{L}^{-1}$ in 10-20 wt\% $\mathrm{HCl}$ ) were purchased from Chem-Lab (Zedelgem, Belgium). HCl (37 wt\%) was acquired from VWR (Leuven, Belgium). $\mathrm{FeCl}_{3}$ (99\%) was bought from Honeywell Riedel de Haën (Seelze, Germany). $\mathrm{PdCl}_{2}$ (99.9\%) and $\mathrm{CuBr}_{2}$ (99\%) were obtained from J\&K Scientific (Lommel, Belgium). Tubing, junctions and fittings were acquired from IDEX Health \& Science. Water was of ultrapure quality, deionized with a Merck Millipore Milli-Q ${ }^{\circledR}$ Reference A+ system. All chemicals were used as received, without any further purification.

\subsection{Ionic liquid synthesis}

The bromide ionic liquid [A336][Br] was prepared by contacting an aliquot of [A336][Cl] four times with an equal volume of a $2 \mathrm{~mol} \mathrm{~L}^{-1} \mathrm{NaBr}$ solution. The synthesized [A336][Br] was then washed at least two times with an equal volume of ultrapure water to remove any dissolved salts. The absence of chlorides was checked using a qualitative total reflection X-ray fluorescence (TXRF) measurement on a Bruker S2 Picofox TXRF, operated with a 
molybdenum source at $50 \mathrm{kV}$. Measurements were performed over $300 \mathrm{~s}$ on a $2 \mu \mathrm{L}$ ionic liquid droplet placed on a quartz sample carrier (limit of detection: 20 ppm of Cl).[54]

\subsection{Experimental procedure}

Two Vici M50HP pulse-free, positive displacement pumps were used to deliver both the metal containing aqueous feed solution and the ionic liquid to a T-junction. Prior to the experiment, the ionic liquid was pre-equilibrated with a metal-free solution of the same acid or salt concentration as the experimental conditions in order to avoid volume changes during the extraction. The aqueous feed solutions were prepared by diluting a certain volume of an aqueous metal stock solution with ultrapure water and an acid or a salt solution ( $\mathrm{HCl} 37 \mathrm{wt} \%$, $\mathrm{HBr} 48$ wt \%, 4 mol L-1 $\mathrm{NaCl}$ or $4 \mathrm{~mol} \mathrm{~L}^{-1} \mathrm{NaBr}$, depending on the studied system). The Tjunction was mounted such that the ionic liquid, which would form the continuous phase due to the hydrophobic nature of the tubing material, was allowed to flow straight into the perfluoroalkoxy alkane (PFA) reaction channel while the aqueous phase was introduced perpendicularly. A configuration with the viscous ionic liquid as the continuous phase is preferred as this results in the most intense internal circulations and minimizes plug slippage.[32,55] The T-junction through-hole was matched with the reactor channel inner diameter (ID). For each new set of experimental conditions, ten times the reactor volume was flowed through the system before sampling in order to ensure a stable flow pattern and a complete renewal of both liquids in the channel. Triplicate samples were collected in $1.5 \mathrm{~mL}$ Eppendorf vials at the end of the reactor channel, their volume dependent on the minimal required volume for ICP-OES analysis and the used dilution factor. The samples were centrifuged for approximately $10 \mathrm{~s}$ using a VWR MiniStar centrifuge and phase separated. The error induced by the sampling and centrifugation times on the metal extraction is ignored as the 
influence of diffusive extraction is expected to be minimal due to rapid settling and the absence of agitation.[55]

High-speed imaging was performed in a separate set of experiments where the reactor channel was suspended in a custom-made water bath. This was important to lower the distortion of the images caused by the round wall of the PFA tubing by minimizing the difference in refractory index between the tubing material and its surroundings. The remaining error on the measured ratio of the inner and outer tube diameter was between 4 and 5\%. Images were taken $10 \mathrm{~cm}$ after the T-junction.

Equilibrium extraction experiments were performed in $4 \mathrm{~mL}$ glass vials on a total liquid volume of $1 \mathrm{~mL}$. Equilibrium was attained by shaking laterally at $2500 \mathrm{rpm}$ for $60 \mathrm{~min}$ at room temperature using a TMS-200 Turbo Thermo Shaker (Allsheng Instruments). Phase separation was promoted by centrifugation for 3 min at 5000 rpm using a Heraeus Labofuge 200 centrifuge (Thermo Scientific).

\subsection{Instrumentation, analysis and quantification methods}

Aqueous metal concentrations were measured using a PerkinElmer Optima 8300 Inductively Coupled Plasma Optical Emission Spectrometer (ICP-OES) equipped with an axial/radial dual plasma view, a GemTip Cross-Flow II nebulizer, a Scott double pass with inert Ryton spray chamber, a demountable one-piece Hybrid XLT ceramic torch with a $2.0 \mathrm{~mm}$ internal diameter sapphire injector, an echelle-based polychromator, and a two-dimensional, segmented CCD array solid state detector. Samples were diluted with a 2 vol \% $\mathrm{HNO}_{3}, 2 \mathrm{vol} \% \mathrm{HCl}$, and $0.5 \mathrm{wt}$ \% L-cysteine solution. The additional complexing power of $\mathrm{HCl}$ and L-cysteine was required to

prevent a memory effect i.e. long wash-in and wash-out times for $\mathrm{Au}(\mathrm{III})$.[56,57] For experiments where $\mathrm{Au}(\mathrm{III})$ was not present or where its quantification was not necessary, 
samples were diluted with 2 vol \% $\mathrm{HNO}_{3}$. Calibration was performed using solutions containing $0.1,1,5$, and $10 \mathrm{mg} \mathrm{L}^{-1}$ of the corresponding metal. Y(III) and $\mathrm{Ga}(\mathrm{III})$ were added as internal standards (5 mg L ${ }^{-1}$ ), but were applied only in case matrix effects were observed. All spectra were collected in triplicate and a quality control was performed regularly using a $1 \mathrm{mg} \mathrm{\textrm {L } ^ { - 1 }}$ solution of the corresponding metals.

Aqueous metal concentrations were measured before and after extraction which allowed the calculation of the organic metal concentration (Equation 1) and extraction efficiency (Equation 2).

$$
\begin{gathered}
\mathrm{C}_{\mathrm{M}, \text { org, }}=\frac{\left(\mathrm{C}_{\mathrm{M}, \mathrm{aq}, \mathrm{i}}-\mathrm{C}_{\mathrm{M}, \mathrm{aq}, \mathrm{f}}\right)}{\mathrm{O} / \mathrm{A}} \\
\% E=\frac{\mathrm{O} / \mathrm{A} \mathrm{C}_{\mathrm{M}, \mathrm{org}, \mathrm{f}}}{\mathrm{C}_{\mathrm{M}, \mathrm{aq}, \mathrm{i}}} * 100
\end{gathered}
$$

with $\mathrm{C}_{\mathrm{M}, \text { org, }}$ the final concentration of metal $\mathrm{M}$ in the organic phase after extraction, $\mathrm{C}_{\mathrm{M}, \mathrm{aq}, \mathrm{i}}$ and $\mathrm{C}_{\mathrm{M}, \mathrm{aq}, \mathrm{f}}$ the concentration of metal $\mathrm{M}$ in the aqueous phase before and after extraction, respectively, and $\mathrm{O} / \mathrm{A}$ the applied organic-to-aqueous volumetric flow rate ratio.

The distribution ratio $D$ is defined as the ratio of the organic and aqueous metal concentrations at equilibrium (Equation 3). The decontamination factor $S_{\mathrm{M} 1 / \mathrm{M} 2}$ quantifies the increase in the ratio of contaminant (M2) to metal of interest (M1) concentrations after extraction compared to the feed solution and it can be related to the extraction efficiencies of both elements (Equation 4). A mass-based purity $P_{\mathrm{M} 1 / \mathrm{M} 2}$ of the extracted metal of interest M1 in terms of co-extraction of the impurity M2 is defined according to Equation 5.

$$
\begin{gathered}
D=\frac{\mathrm{C}_{\mathrm{M}, \text { org,f }}}{\mathrm{C}_{\mathrm{M}, \mathrm{aq}, \mathrm{f}}} \\
S_{\mathrm{M} 1 / \mathrm{M} 2}=\frac{\left(\mathrm{C}_{\mathrm{M} 2, \mathrm{aq}, \mathrm{i}} / \mathrm{C}_{\mathrm{M} 1, \mathrm{aq}, \mathrm{i}}\right)}{\left(\mathrm{C}_{\mathrm{M} 2, \text { org, }} / \mathrm{C}_{\mathrm{M} 1, \text { org, } \mathrm{f}}\right)}=\frac{\% E_{\mathrm{M} 1}}{\% E_{\mathrm{M} 2}}
\end{gathered}
$$




$$
P_{\mathrm{M} 1 / \mathrm{M} 2}=\frac{\mathrm{m}_{\mathrm{M} 1, \mathrm{org}, \mathrm{f}}}{\mathrm{m}_{\mathrm{M} 1, \mathrm{org}, \mathrm{f}}+\mathrm{m}_{\mathrm{M} 2, \text { org, } \mathrm{f}}}
$$

with $m_{M 1, o r g, f}$ the mass of the metal of interest in the organic phase after extraction and $m_{M 2, o r g, f}$ the mass of the contaminant metal in the organic phase after extraction.

High-speed images were taken using a Photron FASTCAM Mini UX equipped with a Navitar $12 \times$ optical zoom lens at a resolution of $1280 \times 1024$ and a frame rate of 2000 frames per second. Backlighting was provided by a Schott KL 1600 LED light source. Image analysis and the measurement of hydrodynamic parameters was performed using the ImageJ software. The known outer diameter of the tubing was used as scale. The plug length, $\mathrm{L}_{\mathrm{p}}$, was measured on the channel center line while the plug height or width, $\mathrm{H}_{\mathrm{p}}$, was measured on the plug section of uniform thickness. If the latter was not available e.g. for large O/A values, $\mathrm{H}_{\mathrm{p}}$ was measured in the center of the plug. For a certain set of experimental conditions, measurements of at least three different images and five separate plugs were averaged. High-speed image analysis was also used for the assessment of the actual plug residence time $\tau$. Due to the presence of a relatively large wall film, this residence time differed significantly from the theoretical residence time $\tau_{\text {th }}$ calculated from the applied total flow rate Q:

$$
\tau_{\text {th }}=\frac{\pi\left(\frac{\mathrm{ID}}{2}\right)^{2} \mathrm{~L}}{\mathrm{Q}} * 60
$$

with $\tau_{\text {th }}$ the theoretical residence time in s, ID the inner diameter of the reactor in $\mathrm{m}$, $\mathrm{L}$ the length of the reactor in $\mathrm{m}$ and $\mathrm{Q}$ the total applied flow rate in $\mathrm{m}^{3} \mathrm{~min}^{-1}$. The velocity of the aqueous plugs $U_{p}$ was determined based on their displacement between consecutive images. For each applied set of extraction conditions, a linear fitting of $U_{p}$ in $\mathrm{m} \mathrm{s}^{-1}$ as a function of $\mathrm{Q}$ was then used to calculate the actual residence time $\tau$ for any value of $\mathrm{Q}$.

$$
\tau=\frac{\mathrm{L}}{\mathrm{U}_{\mathrm{p}}}=\frac{\mathrm{L}}{\mathrm{aQ}+\mathrm{b}}
$$


with $a$ and $b$ the slope and intercept, respectively, of the $U_{p}$ versus $Q$ linear fit (cfr. Figure 8c). 


\section{Results and discussion}

\subsection{Improvement of $\mathrm{Au} / \mathrm{Pd} / \mathrm{Cu} / \mathrm{Fe}$ separation by non-equilibrium extraction}

In a first flow experiment on the $\mathrm{Au}(\mathrm{III}) / \mathrm{Pd}(\mathrm{II}) / \mathrm{Cu}(\mathrm{II}) / \mathrm{Fe}(\mathrm{III})$ separation, $500 \mathrm{ppm}$ of each metal was extracted from a $0.5 \mathrm{~mol} \mathrm{~L}^{-1} \mathrm{HX}(\mathrm{X}=\mathrm{Cl}$ or $\mathrm{Br})$ solution using undiluted [A336][Cl] and [A336][Br], respectively. A schematic representation of the experimental set-up is shown in Figure 1. The experiment was performed using a reactor with an internal diameter of $1.0 \mathrm{~mm}$ and $\mathrm{O} / \mathrm{A}=1$, the residence time was varied by changing both the total applied flow rate (140 $\left.1500 \mu \mathrm{L} \mathrm{min}{ }^{-1}\right)$ and the reactor length $(10-40 \mathrm{~cm})$. Low aqueous halide concentrations were chosen as this gives the best precious/base metal separations at equilibrium conditions i.e. least amount of $\mathrm{Cu}(\mathrm{II})$ and $\mathrm{Fe}(\mathrm{III})$ co-extraction, consequently also the most significant nonequilibrium enhancement would be expected (vide infra).[53] The results are shown in Figure $2 \mathrm{a}$ and $2 \mathrm{~b}$ for the chloride and bromide systems, respectively. The results clearly show that the extraction of the precious metals is fast compared to extraction of the base metals: complete $\mathrm{Au}(\mathrm{III})$ and $\mathrm{Pd}(\mathrm{II})$ extraction is achieved within $25 \mathrm{~s}$, whereas equilibrium values could not be attained for $\mathrm{Fe}(\mathrm{III})$ and $\mathrm{Cu}(\mathrm{II})$ within the studied time frame. Equilibrium values are represented by the dashed lines and are only shown in case they are smaller than $99.9 \%$, i.e. when no equilibrium line is shown, equilibrium extraction is quantitative $(\approx 100 \%)$. In terms of $\mathrm{Au}(\mathrm{III})$ and Pd(II) extraction, both halide systems perform similarly, i.e. Au(III) extraction seems to be slightly faster than Pd(II) extraction. The main difference between the halide systems is the extraction of $\mathrm{Fe}(\mathrm{III})$ and $\mathrm{Cu}(\mathrm{II})$, with the extraction of $\mathrm{Fe}(\mathrm{III})$ most efficient in the chloride medium and the extraction of $\mathrm{Cu}(\mathrm{II})$ most efficient in the bromide system. This observation can be explained qualitatively as $\mathrm{Cu}(\mathrm{II})$ is a softer Lewis acid than $\mathrm{Fe}(\mathrm{III})$ and tends to associate more readily with the softer bromide anions. 


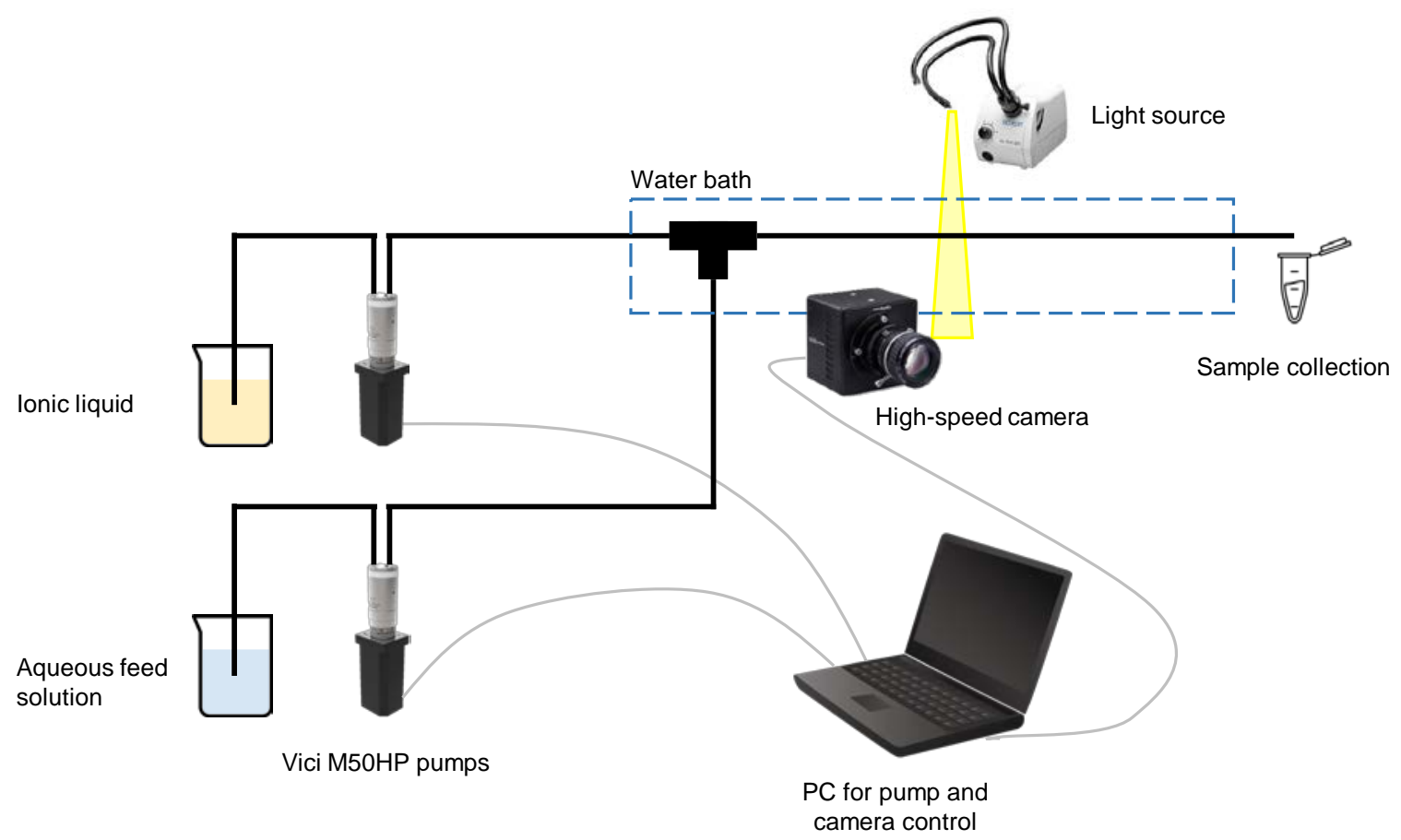

Figure 1: Schematic representation of the experimental set-up. 


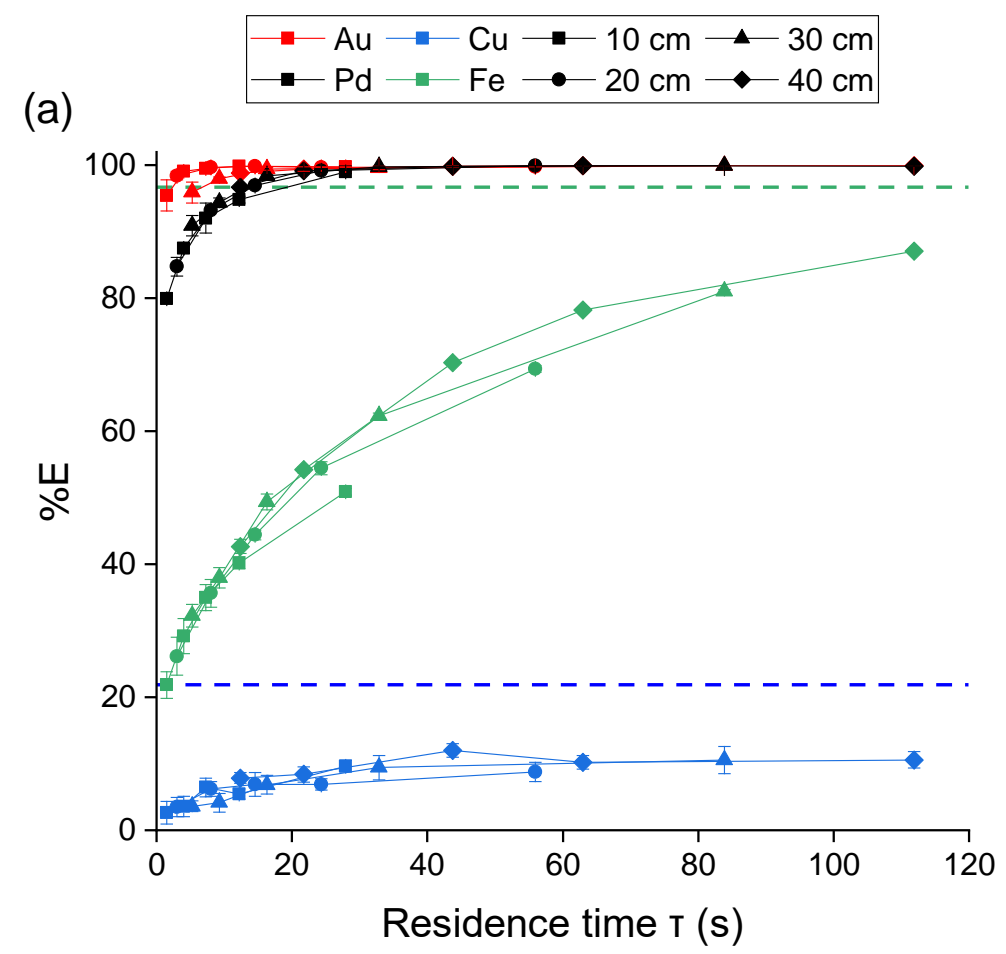

(b)

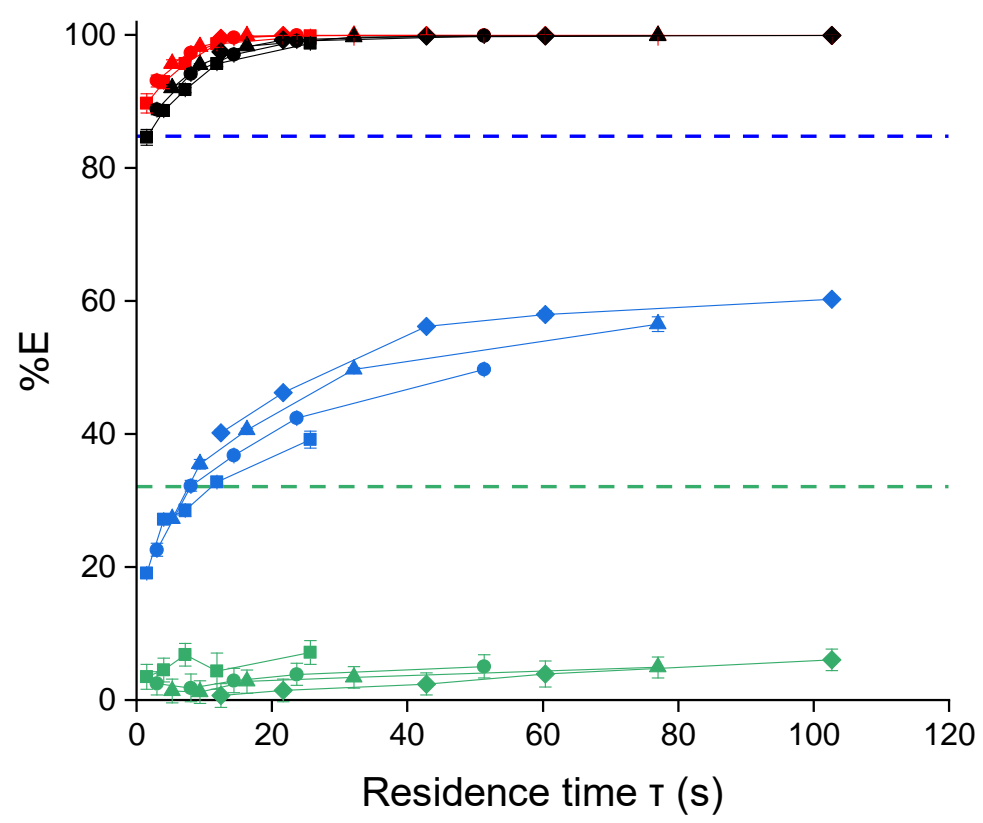

Figure 2: Extraction efficiency of 500 ppm Au(III), 500 ppm Pd(II), 500 ppm Cu(II) and 500 ppm Fe(III) as a function of residence time (a) $0.5 \mathrm{~mol} \mathrm{~L}^{-1} \mathrm{HCl}$ and [A336] [Cl], (b) $0.5 \mathrm{~mol} \mathrm{~L}-$ ${ }^{1} \mathrm{HBr}$ and [A336][Br]. Dashed lines represent equilibrium values. Experimental conditions: $1.0 \mathrm{~mm} \mathrm{ID,} \mathrm{O/A} \mathrm{1,} \mathrm{total} \mathrm{flow} \mathrm{rate} 140-1500 \mu \mathrm{L} \mathrm{min}{ }^{-1}$, tube length $10-40 \mathrm{~cm}$, room temperature.

A significant fraction of the mass transfers occurs already very early in the channel, i.e. the first $5 \mathrm{~s}$, after which the increase in $\% E$ is slower. Literature data show that up to $40 \%$ of the mass 
transfer occurs already in the first mm of the channel during slug formation.[27,47] Once the slug flow and the circulation vortices have developed, the extraction depends mainly on the diffusion between the concentration gradients and hence slows down. Comparing the extraction efficiencies of different reactor lengths but equal residence times, it can be seen that the applied flow rate has a small influence on the mass transfer. Higher flow rates are related to stronger internal circulations and increased mass transfer rates, hence an increased extraction efficiency can be observed for the longer reactors which require a higher flow rate for a certain residence time.[46,47] This can most clearly be seen for Fe(III) extraction with [A336][Cl] and $\mathrm{Cu}(\mathrm{II})$ extraction with [A336][Br]. It is important to note that this observation can only clearly be seen when the extraction is plotted as a function of the actual residence time $\tau$ which is based on high speed imaging. When the theoretical residence time $\tau_{\text {th }}$ based on the volumetric throughput would be used, the wrong conclusion would be drawn that the applied flow rate has practically no influence on the extraction performance. Making the distinction between $\tau$ and $\tau_{\text {th }}$ is most likely more important for these viscous ionic liquids than for non-viscous solvents due to a more substantial film which surrounds the plugs.

Because of the observed differences in extraction rate, an improved precious/base metal separation can be envisioned by working at non-equilibrium conditions. It is important to note that in this case the thermodynamic selectivity of the used extraction system remains superimposed on the possible enhancement offered by non-equilibrium. This means for example that a separation of $\mathrm{Au}(\mathrm{III})$ or Pd(II) from $\mathrm{Fe}(\mathrm{III})$ would still be preferably performed in a bromide system notwithstanding the significant reduction of Fe(III) co-extraction that can be achieved in the non-equilibrium chloride system. Ideally, system thermodynamics and kinetics go hand in hand to achieve the best separation. For example, the separation of $\mathrm{Au}(\mathrm{III})$ or Pd(II) from a solution with Fe(III) as the main contaminant and smaller amounts of $\mathrm{Cu}(\mathrm{II})$ 
should be performed using the bromide system to minimize the total amount of base metal coextraction. And vice versa, if $\mathrm{Cu}(\mathrm{II})$ is the main contaminant, the chloride system is preferred.

Such an enhancement or improvement in separation would often be quantified in terms of separation factors i.e. the ratio of distribution ratios.[43,44] However, the efficient $\mathrm{Au}(\mathrm{III})$ and Pd(II) extraction (for some conditions $D>1000$ ) would result in a significant error on this separation factor and obstruct the correct evaluation of the observations. Therefore, the use of alternative metrics such as the decontamination factor (Equation 4) or product purity (Equation 5) is preferred for the evaluation of the enhancement in separation. Figure 3 depicts the decontamination factors of $\mathrm{Au}(\mathrm{III})$ and $\mathrm{Pd}(\mathrm{II})$ for $\mathrm{Fe}(\mathrm{III})$ co-extraction, $S_{\mathrm{Au}(\mathrm{III}) / \mathrm{Fe}(\mathrm{III})}$ and

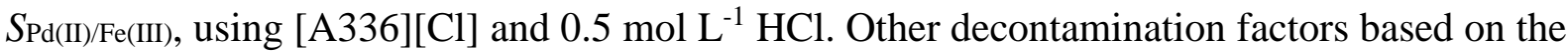
results of Figure 2 show a similar increase at short residence times. Working at a minimum residence time of $25 \mathrm{~s}$ for a full recovery of $\mathrm{Au}(\mathrm{III})$ or $\mathrm{Pd}(\mathrm{II})$, decontamination factors can be increased with a factor of 1.7 to 2 compared with equilibrium conditions. Depending on which system and elements are considered, this relates to an extracted product purity increase of 4 to $14 \%$. If a complete recovery of the precious metals is not required or when a multistage process is employed to ensure their complete extraction, the contact time may be limited to less than 25 s and even higher decontamination factors and product purities may be achieved. 

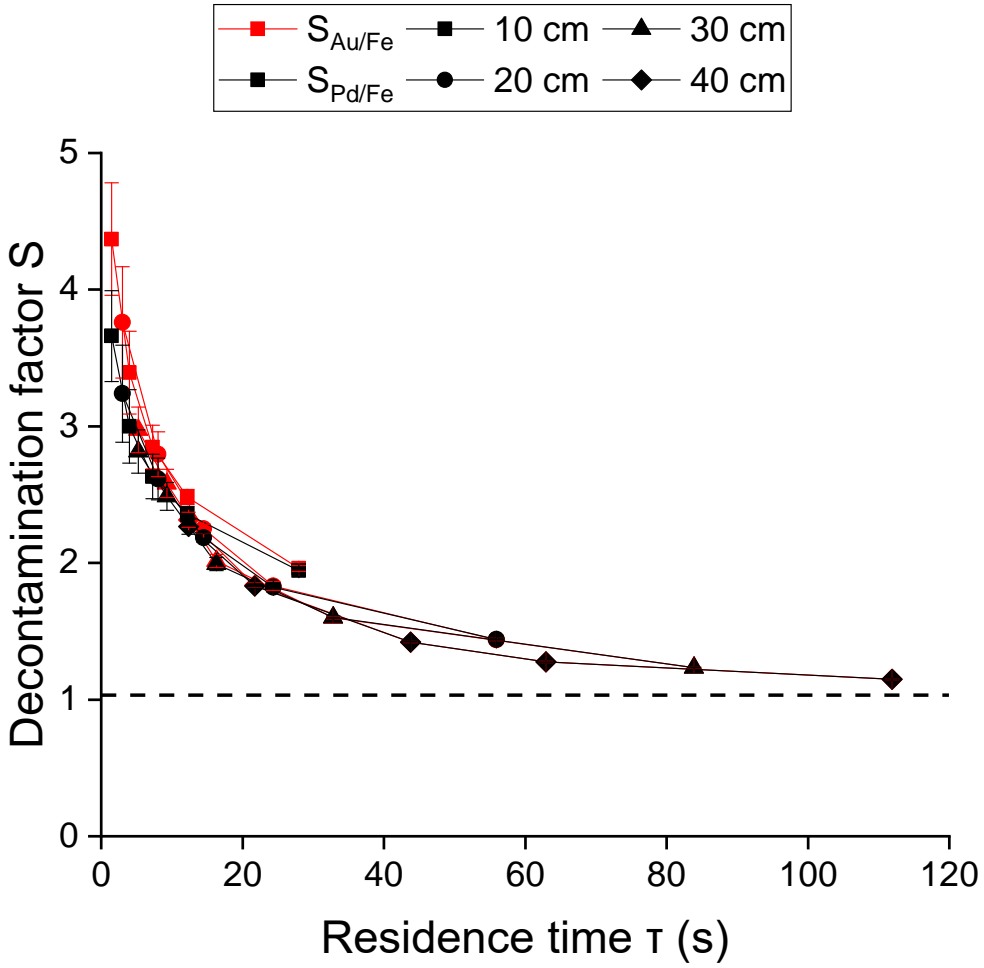

Figure 3: Decontamination factors of $\mathrm{Au}(\mathrm{III})$ and $\mathrm{Pd}(\mathrm{II})$ for Fe(III) co-extraction as a function of residence time for the extraction of $500 \mathrm{ppm} A \mathrm{Au}(\mathrm{III}), 500 \mathrm{ppm} \mathrm{Pd}(\mathrm{II}), 500 \mathrm{ppm}$

$\mathrm{Cu}(\mathrm{II})$ and $500 \mathrm{ppm} \mathrm{Fe}(\mathrm{III})$ from $0.5 \mathrm{~mol} \mathrm{~L}^{-1} \mathrm{HCl}$ using [A336][Cl]. The dashed line represents equilibrium.

The precious metal chloro- and bromo-complexes are generally more stable and rather kinetically inert towards ligand substitution compared with the corresponding base metal complexes.[58,59] Consequently, the solvent extraction of these metals is often found to be slow when ligand substitution is required e.g. for extractants like di-n-octyl sulfide or LIX 84.[60] [A336][Cl] and $[\mathrm{A} 336][\mathrm{Br}]$, however, are basic extractants and their extraction mechanism is usually described as an anion exchange process:

$$
\mathrm{MX}_{\mathrm{y}}{ }^{\mathrm{n}-}{ }_{\mathrm{aq}}+\mathrm{nQ}^{+} \mathrm{X}^{-}{ }_{\text {org }} \rightleftharpoons \mathrm{Q}_{\mathrm{n}}^{+} \mathrm{MX}_{\mathrm{y}}^{\mathrm{n}{ }_{\text {org }}^{-}}+\mathrm{nX}_{\mathrm{aq}}^{-}
$$

with $\mathrm{M}$ the respective metal, $\mathrm{X}^{-}$a coordinating anion (e.g. $\mathrm{Cl}^{-}$and $\left.\mathrm{Br}^{-}\right)$and $\mathrm{Q}^{+}$an organic cation. Equation 8 shows that for this type of extractant no complexation or ligand substitution reactions are required in order for metal extraction to occur if the metal is present as an anionic 
species in the aqueous phase. As the latter is generally the case for precious metal halide solutions, metal extraction is expected to proceed without much difficulty.[58] Moreover, for $\mathrm{Au}(\mathrm{III})$ and $\mathrm{Pd}(\mathrm{II})$ the equilibrium in Equation 8 is shifted significantly to the right at low halide concentrations $(D>1000)$ which most likely also contributes to their rapid extraction compared to $\mathrm{Cu}(\mathrm{II})$ and $\mathrm{Fe}(\mathrm{III})$ (vide infra).

\subsection{Effect of halide concentration}

For basic extractants, the formation of anionic complexes and the anion concentration (i.e. halide concentration in this particular case) are the main parameters which control the extraction and separation of metals (cfr. Equation 8). The preceding paragraph discussed the separation of $\mathrm{Au}(\mathrm{III}), \mathrm{Pd}(\mathrm{II}), \mathrm{Cu}(\mathrm{II})$ and $\mathrm{Fe}(\mathrm{III})$ under rather ideal conditions i.e. low halide concentrations. Elevated halide concentrations result in increased equilibrium extraction efficiencies for both $\mathrm{Cu}(\mathrm{II})$ and $\mathrm{Fe}(\mathrm{III})$ while the extraction of $\mathrm{Au}(\mathrm{III})$ and $\mathrm{Pd}(\mathrm{II})$ remains fully efficient (i.e. $\% E \approx$ 100\%) for both halide systems.[53] The effect of increased halide concentrations, where the equilibrium separation is expected to be poorer, is discussed here. Only data on the chloride system are shown as the results and conclusions for the bromide system are similar with the exception of a reversed $\mathrm{Cu}(\mathrm{II}) / \mathrm{Fe}(\mathrm{III})$ selectivity. Data on the bromide system are provided in the Supporting Information (SI) Figure S1 and S2. Figure 4 shows the extraction of $\mathrm{Au}(\mathrm{III})$, Pd(II), $\mathrm{Cu}(\mathrm{II})$ and $\mathrm{Fe}(\mathrm{III})$ from various $\mathrm{HCl}$ and $\mathrm{NaCl}$ concentrations using [A336][Cl]. The experiment was performed using a $20 \mathrm{~cm}$ long $1.0 \mathrm{~mm}$ ID reactor and $\mathrm{O} / \mathrm{A} 1$, the residence time was varied by changing the total applied flow rate $\left(140-1500 \mu \mathrm{L} \min ^{-1}\right)$. The increased chloride concentration resulted in a slight decrease in the extraction rate of $\mathrm{Au}(\mathrm{III})$ and $\mathrm{Pd}(\mathrm{II})$ which can be inferred from the lowered extraction efficiencies, especially for the first $15 \mathrm{~s}$. For $\mathrm{Cu}(\mathrm{II})$ and $\mathrm{Fe}(\mathrm{III})$, not only an increased equilibrium extraction efficiency is observed but also 
a significant increase in extraction rate, i.e. the equilibrium extraction efficiency is approached more rapidly. Despite this, the extraction of the precious metals remains markedly faster than the base metals and the benefit from working at non-equilibrium conditions remains present for most halide concentrations. However, the achievable decontamination factor or product purity can be significantly reduced. This is illustrated in Figure 5 for $P_{\mathrm{Au}(\mathrm{IIII} / \mathrm{Cu}(\mathrm{II})}$ and $S_{\mathrm{Pd}(\mathrm{II}) / \mathrm{Fe}(\mathrm{III}) \text {. For }}$ example in Figure 5a, considering again 25 s residence time for adequate Au(III) recovery, $P_{\mathrm{Au}(\mathrm{III}) / \mathrm{Cu}(\mathrm{II})}$ is reduced with $20 \%$ when the $\mathrm{HCl}$ concentration is increased from 0.5 to $4 \mathrm{~mol} \mathrm{\textrm {L } ^ { - }}$ ${ }^{1}$. However, even for $4 \mathrm{~mol} \mathrm{~L}^{-1} \mathrm{HCl}$ equilibrium values are not reached after $25 \mathrm{~s}$ and some enhancement in separation remains possible. Figure $5 b$ shows that at chloride concentrations $>3 \mathrm{~mol} \mathrm{~L}^{-1}$ the extraction rate of $\mathrm{Fe}(\mathrm{III})$ becomes so similar to that of $\mathrm{Pd}(\mathrm{II})$ (or $\mathrm{Au}(\mathrm{III})$ ) that the benefit of working at non-equilibrium conditions is lost. This issue is not encountered for $\mathrm{Cu}(\mathrm{II})$ (Figure 5a) due to its less efficient extraction in the chloride system. 


$\longrightarrow 0.5 \mathrm{M} \mathrm{HCl} \longrightarrow 6 \mathrm{M} \mathrm{HCl} \longrightarrow 2 \mathrm{M} \mathrm{HCl} \longrightarrow 4 \mathrm{M} \mathrm{HCl}$
$\multimap-6 \mathrm{M} \mathrm{HCl} \longrightarrow 3 \mathrm{M} \mathrm{NaCl}$
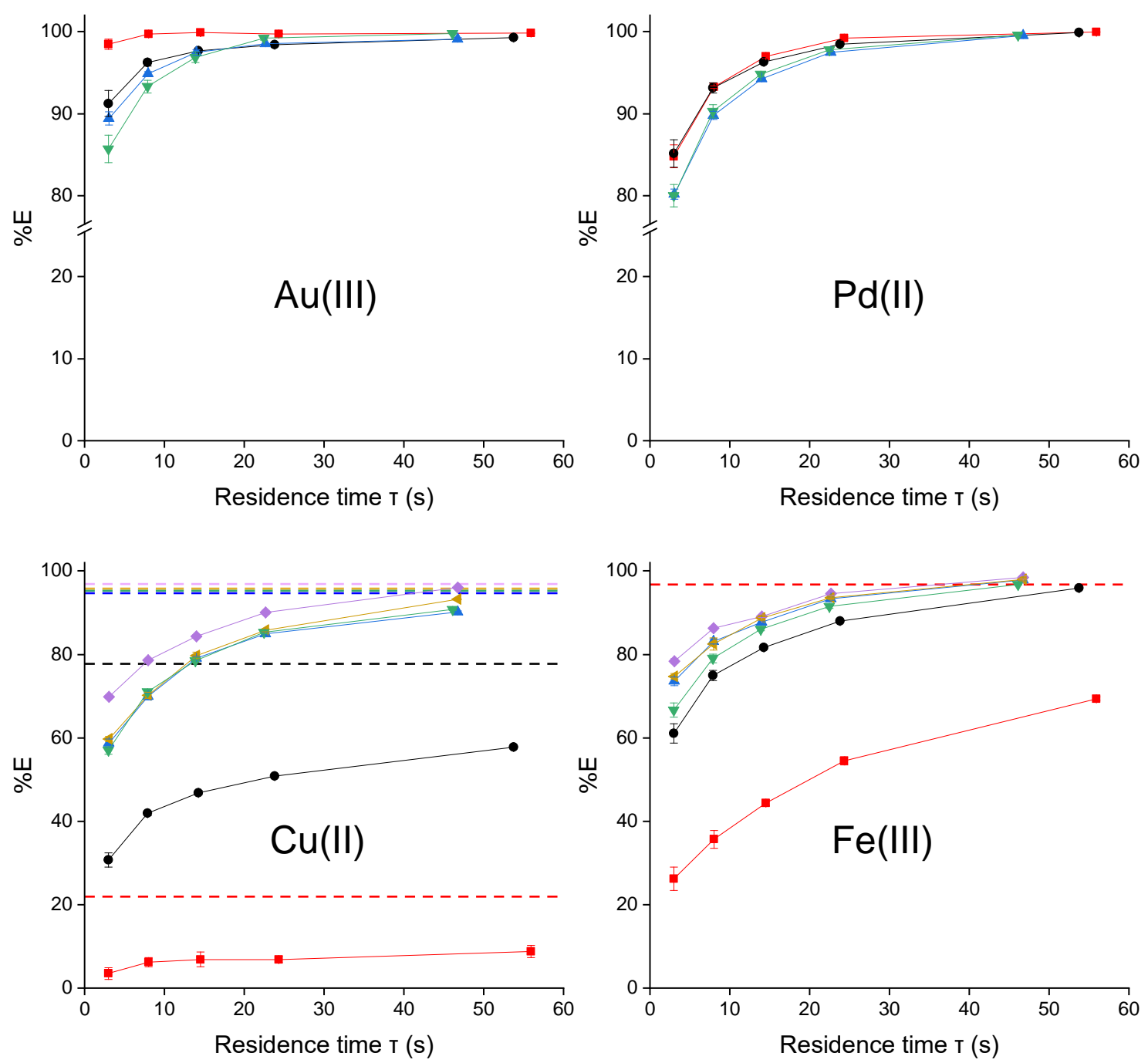

Figure 4: Extraction efficiency of 500 ppm Au(III), 500 ppm Pd(II), 500 ppm Cu(II) and 500 ppm $\mathrm{Fe}(\mathrm{III})$ with [A336][Cl] as a function of residence time and chloride concentration. Dashed lines represent equilibrium values. Experimental conditions: tube length $20 \mathrm{~cm}, 1.0$ $\mathrm{mm} I D, O / A 1$, total flow rate $140-1500 \mu \mathrm{L} \mathrm{min}^{-1}$, room temperature. 


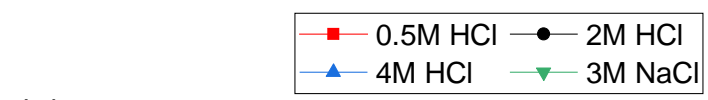

(a)

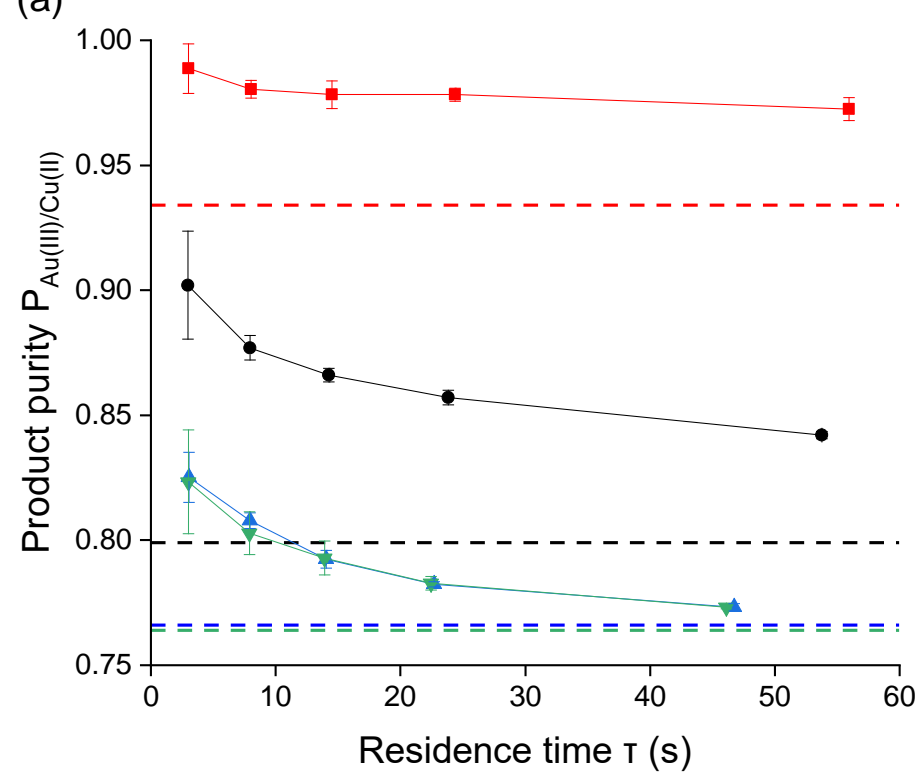

(b)

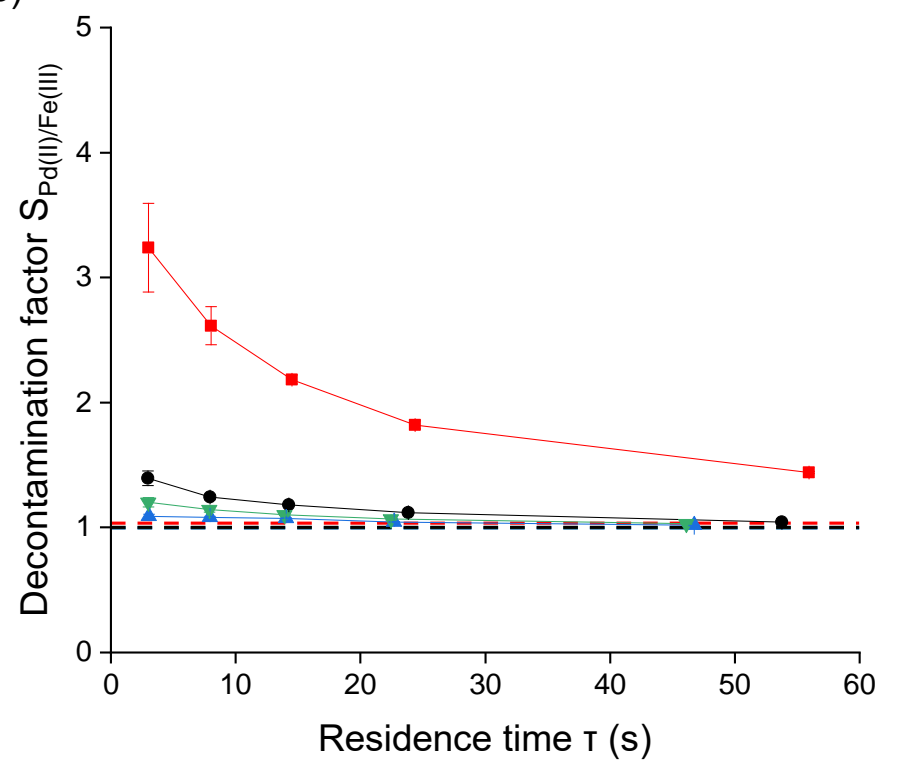

Figure 5: (a) Product purity of $\mathrm{Au}(\mathrm{III})$ for $\mathrm{Cu}(\mathrm{II})$ co-extraction and (b) decontamination factor of Pd(II) for Fe(III) co-extraction as a function of residence time and chloride concentration for the extraction of $500 \mathrm{ppm} \mathrm{Au}(\mathrm{III}), 500 \mathrm{ppm} P d(\mathrm{II}), 500 \mathrm{ppm} \mathrm{Cu}(\mathrm{II})$ and 500 ppm Fe(III) using [A336][Cl]. Dashed lines represent equilibrium values.

A change in the aqueous halide concentration can influence the extraction and separation process in several ways. Important are, for example, the aqueous metal speciation, the possible required changes thereof cfr. Equation 8 and the equilibrium position of the extraction process 
i.e. the equilibrium distribution ratio $D$. How both factors might relate to the observed differences in extraction rate in Figure 4 is subsequently discussed on a qualitative basis. A full and thorough description of the origin of the different extraction rates would require, among other things, a study of the interfacial effects, mixing intensity and rate-determining reaction steps and is outside the scope of current study.[5]

At the lowest studied chloride concentration $\left(0.5 \mathrm{~mol} \mathrm{~L}^{-1} \mathrm{HCl}\right)$, both $\mathrm{Au}(\mathrm{III})$ and $\mathrm{Pd}(\mathrm{II})$ are already present in solution as anionic chloride complexes i.e. $\left[\mathrm{AuCl}_{4}\right]^{-}$and $\left[\mathrm{PdCl}_{4}\right]^{2-} \cdot[61,62]$ According to Equation 8, a chloride ion is sent to the aqueous phase upon extraction, and this becomes more and more difficult as the chloride concentration increases. Hence a decrease in the extraction rate can be expected. $\mathrm{Cu}(\mathrm{II})$ and $\mathrm{Fe}(\mathrm{III})$ speciation at $0.5 \mathrm{~mol} \mathrm{~L}^{-1} \mathrm{HCl}$ is characterized with cationic aquated or monochloro complexes.[63,64] As the chloride concentration increases, the formation of anionic complexes is promoted and the extraction rate can be expected to increase. At a certain chloride concentration, the extraction rate slows down again due to the difficult back-extraction of the chloride ion. This can be observed in Figure 4 for $\mathrm{Cu}(\mathrm{II})$ when going from 6 to $8 \mathrm{~mol} \mathrm{~L}^{-1} \mathrm{HCl}$. However, recently some observations on metal extraction with basic extractants have shed doubt on the thermodynamic steps behind the above mentioned extraction mechanism.[64] It was postulated that extraction does not necessarily proceed by extraction of the anionic complexes, but rather that the species least stabilized by hydration, which is often the neutral complex, is extracted to the organic phase. For Au(III) and Pd(II), this means that a loss of chloride ligands is required prior to extraction which becomes more difficult with increasing chloride concentrations. Even though this loss of halide ligand is rather unlikely for the highly stable $\mathrm{Au}(\mathrm{III})$ and $\mathrm{Pd}(\mathrm{II})$ complexes, it might explain the observed decrease in extraction rate of the precious metals. For $\mathrm{Cu}(\mathrm{II})$ and $\mathrm{Fe}(\mathrm{III})$, the increasing chloride concentration initially means the more readily formation of the neutral $\mathrm{CuCl}_{2}$ and $\mathrm{FeCl}_{3}$ complexes and consequently an increase in extraction rate. At a sufficiently high chloride 
concentration, strongly hydrated, anionic complexes will become prominent and the extraction is expected to slow down again. According to the speciation profile of $\mathrm{Cu}(\mathrm{II})$ in chloride media provided by Lommelen et al., the extraction rate of $\mathrm{Cu}(\mathrm{II})$ is expected to be maximum at $4 \mathrm{~mol}$ $\mathrm{L}^{-1} \mathrm{HCl}$ where the speciation is dominated by the $\mathrm{CuCl}_{2}$ neutral complex and expected to decrease at higher concentrations as more and more anionic complexes are formed.[64] However, the data in Figure 4 show that the $\mathrm{Cu}(\mathrm{II})$ extraction rate is maximum for $6 \mathrm{~mol} \mathrm{~L}^{-1}$ $\mathrm{HCl}$. Moreover, the extraction rate at 4 and $8 \mathrm{~mol} \mathrm{~L}^{-1} \mathrm{HCl}$ are nearly identical, despite the speciation being entirely different. For Fe(III) extraction, a reduction at elevated chloride concentrations is not observed even though the formation of neutral and/or anionic complexes can be expected at the highest chloride concentrations.[65] Concluding these observations and regardless of how accurately Equation 8 describes the extraction process, it seems that the aqueous metal speciation or required changes thereof are able to correctly predict some of the observed changes in extraction rate with chloride concentration. However, this is only the case for the lower chloride concentrations as discrepancies occur at higher $\left(>4 \mathrm{~mol} \mathrm{~L}^{-1} \mathrm{HCl}\right)$ values. Moreover, this description also fails in explaining why the observed extraction rates differ so much for the different metals. The existence of anionic aqueous metal complexes, e.g. for both $\mathrm{Au}(\mathrm{III})$ and $\mathrm{Pd}(\mathrm{II})$, is not a guarantee for rapid extractions as can be inferred from the decreased extraction rate of $\mathrm{Cu}(\mathrm{II})$ at $8 \mathrm{~mol} \mathrm{~L}^{-1} \mathrm{HCl}$ where its speciation is dominated by the $\left[\mathrm{CuCl}_{3}\right]^{-}$and $\left[\mathrm{CuCl}_{4}\right]^{2-}$ complexes.

A relation between system kinetics (i.e. the observed extraction rates) and thermodynamics (i.e. equilibrium $D$ ) is not evident, if it even exist at all. Reaction kinetics are governed by either mass transfer limitations or rate-determining reaction steps (e.g. complexation changes) and not by the thermodynamic equilibrium position of said reaction. However, the importance of the thermodynamic equilibrium position of a process for the mass transfer performance can be inferred from the inclusion of the partition coefficient (i.e. distribution ratio) or a non-linear 
equilibrium relationship in the calculation of volumetric mass transfer coefficients, kLa.[21] Unfortunately, this inclusion of the equilibrium also means that kLa values cannot be used for the comparison of different chemical systems with different equilibria e.g. different metals or different extraction conditions such as various halide concentrations. For this reason, the calculation of $\mathrm{k}_{\mathrm{La}}$ values has not been considered in current work.

Table 1 shows the equilibrium distribution ratios $D$ of all four elements as a function of the chloride concentration. A decreasing trend is observed for both $\mathrm{Au}(\mathrm{III})$ and $\mathrm{Pd}(\mathrm{II}), \mathrm{Cu}(\mathrm{II})$ shows a maximum at $6 \mathrm{~mol} \mathrm{~L}^{-1} \mathrm{HCl}$ and the distribution ratio of $\mathrm{Fe}(\mathrm{III})$ steeply increases without showing a subsequent decrease. These trends correlate well with the observed changes in extraction rate in Figure 4. In addition, the data in Table 1 give a good indication as to why the difference in extraction rate between the precious and base metals is so large at low chloride concentrations. High equilibrium distribution ratios seem to go along with high extraction rates. This can be qualitatively rationalized as follows: the higher $D$, the further the extraction process is from its equilibrium position at $\tau=0$ resulting in a larger driving force for extraction. The magnitude of $D$, however, cannot explain all observations. For example, at $2 \mathrm{~mol} \mathrm{~L}^{-1} \mathrm{HCl}$, the extraction of $\mathrm{Au}(\mathrm{III})$ is still markedly faster than $\mathrm{Fe}(\mathrm{III})$ even though $\mathrm{Fe}(\mathrm{III})$ displays the largest $D$. These deviations can possibly be linked to other influencing parameters including metal speciation (vide supra), slight changes in liquid properties (e.g. viscosity), complex stability, hydration or charge density, steric hindrance, mass transfer limitations, interfacial processes or other rate-determining reaction steps.

Because of this apparent relationship between $D$ and the extraction rate, it can be concluded that the largest non-equilibrium separation improvement can be achieved at those conditions where the equilibrium or thermodynamic separation is best i.e. where the largest difference in equilibrium $D$ is observed. 
Table 1: Equilibrium distribution ratios D of $\mathrm{Au}(\mathrm{III}), \mathrm{Pd}(\mathrm{II}), \mathrm{Cu}(\mathrm{II})$ and $\mathrm{Fe}(\mathrm{III})$ for extraction to undiluted [A336][Cl] from various chloride concentrations. Adapted from ref. [53].

\begin{tabular}{llllll}
\hline \multicolumn{5}{c}{ Chloride concentrations $\left(\mathrm{mol} \mathrm{L}^{-1}\right)$} \\
\hline $\mathrm{Au}(\mathrm{III})$ & $>1000$ & 645 & 401 & 6 & 8 \\
$\mathrm{Pd}(\mathrm{II})$ & $>1000$ & $>1000$ & $>1000$ & 276 & 84 \\
$\mathrm{Cu}(\mathrm{II})$ & 0.7 & 2.7 & 14 & 31 & 27 \\
$\mathrm{Fe}(\mathrm{III})$ & 130 & $>1000$ & $>1000$ & $>1000$ & $>1000$ \\
\hline
\end{tabular}

\subsection{Effect of phase ratio}

The applied phase ratio or flow rate ratio is an important operational parameter in solvent extraction. Compared with conventional contactors, micro- and millichannels generally have a better ability to optimize the flow rate ratio because design difficulties or mass-transfer limitations can be avoided.[66] The effect of the phase ratio was studied by varying the O/A ratio between $1 / 5$ and $5 / 1$ while working at a constant residence time $\tau$ of about $10 \mathrm{~s}$, by keeping

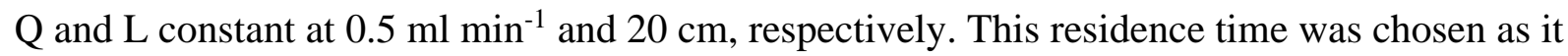
is insufficient for complete $\mathrm{Au}(\mathrm{III})$ or $\mathrm{Pd}(\mathrm{II})$ extraction while not being too short to introduce large errors due to sampling. This way, variations in the extraction efficiency of all four elements would become visible. Figure 6a shows the extraction efficiency of $\mathrm{Au}(\mathrm{III}), \mathrm{Pd}(\mathrm{II})$, $\mathrm{Cu}(\mathrm{II})$ and $\mathrm{Fe}(\mathrm{III})$ from $0.5 \mathrm{~mol} \mathrm{~L}^{-1} \mathrm{HCl}$ using [A336][Cl] as a function of $\mathrm{O} / \mathrm{A}$ ratio. Results for the bromide system are provided in the Supporting Information, Figure S3. A clear decrease in the recovery of all four elements can be seen with an increase in the aqueous phase fraction. This is possibly related to less efficient recirculation vortices in the longer aqueous plugs and/or 
an increased IL viscosity due to the increased metal loading, both can result in less mass transfer within the available time frame.[67] The decrease in extraction efficiency seems to be more significant for the base metals than the precious metals, indicating a preferential loading of $\mathrm{Au}(\mathrm{III})$ and $\mathrm{Pd}(\mathrm{II})$. Consequently, precious metal purities can be increased with 2 to $4 \%$ by working at small O/A ratios instead of the conventional 1/1 ratio, Figure 6b. Working with a smaller organic phase fraction is not only beneficial for the product purity, but it also means a saving in cost as the required ionic liquid inventory can be reduced. 
(a)

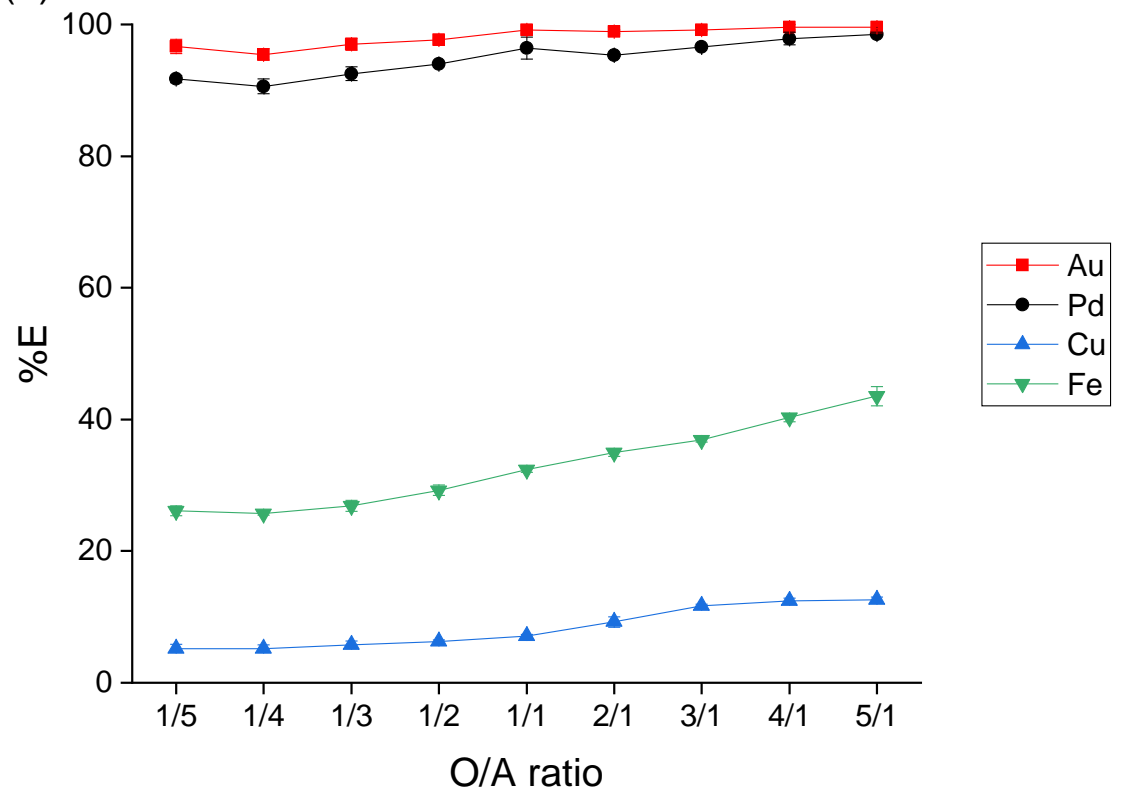

(b)

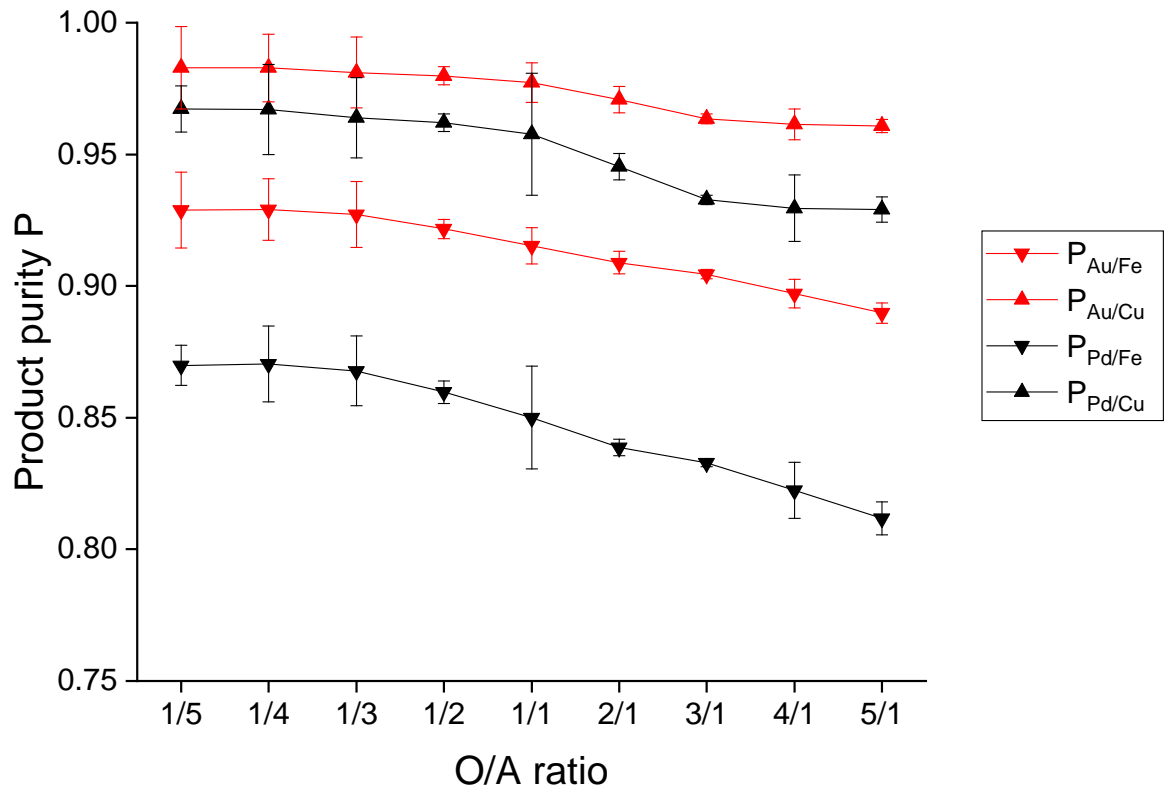

Figure 6: (a) Extraction efficiency of 500 ppm Au(III), 500 ppm Pd(II), 500 ppm Cu(II) and 500 ppm Fe(III) with [A336][Cl] as a function of O/A ratio. (b) Au(III) and Pd(II) product purity for $\mathrm{Cu}(\mathrm{II})$ or $\mathrm{Fe}(\mathrm{III})$ co-extraction as a function of O/A ratio. Experimental conditions: $0.5 \mathrm{~mol} \mathrm{~L}^{-1} \mathrm{HCl}$, tube length $20 \mathrm{~cm}, 1.0 \mathrm{~mm} \mathrm{ID}$, total flow rate $500 \mu \mathrm{L} \mathrm{min} \mathrm{m}^{-1}$, room temperature. 


\subsection{Effect of initial metal concentration}

Besides the halide concentration (vide supra), the initial metal concentration is also important as is apparent from its appearance in the formula for the overall volumetric mass transfer coefficient kLa.[21] Figure 7 shows how a change in initial aqueous metal concentration influences the extraction efficiency of $\mathrm{Au}(\mathrm{III}), \mathrm{Pd}(\mathrm{II}), \mathrm{Cu}(\mathrm{II})$ and $\mathrm{Fe}(\mathrm{III})$ from $0.5 \mathrm{~mol} \mathrm{~L}^{-1} \mathrm{HCl}$ using [A336][Cl]. Extractions were performed using a $20 \mathrm{~cm}$ long $1.0 \mathrm{~mm}$ ID reactor and O/A 1 , the residence time was varied by changing the total applied flow rate $\left(140-1500 \mu \mathrm{L} \mathrm{min}{ }^{-1}\right)$. Data on the bromide system is provided in the Supporting Information, Figure S5 and S6. Both base metals, $\mathrm{Cu}(\mathrm{II})$ and $\mathrm{Fe}(\mathrm{III})$, display a distinct increase in extraction efficiency with increasing metal concentration over the entire residence time range. This increase is most significant from 500 to 1000 ppm, at higher metal concentrations the increase seems to stagnate. For an increased extraction efficiency $\% E$ to be observed, the extraction rate should increase more than proportionally with the metal concentration. For the precious metals $\mathrm{Au}(\mathrm{III})$ and Pd(II), a clear trend is not visible. For the chloride system, the data seem to reflect a slight, relative decrease in extraction efficiency while for the bromide system no such decrease is observed (Figure S5). It seems the precious metal extraction is not significantly affected by the metal concentration due to a proportional increase of the extraction rate and a full recovery still requires approximately $25 \mathrm{~s}$ of residence time.

The increase in base metal extraction rate is similar to what was observed for an increased halide concentration, granted the magnitude of the change is generally smaller. Consequently, a similar but less substantial decrease in product purity and decontamination factor is noticed, examples are provided in the Supporting Information, Figure S4. Considering a residence time of $25 \mathrm{~s}$ for complete precious metal recovery, by increasing the metal concentrations of all four elements from 500 to 1000 ppm, the achievable precious metal product purities are decreased by 3 to $5 \%$. 

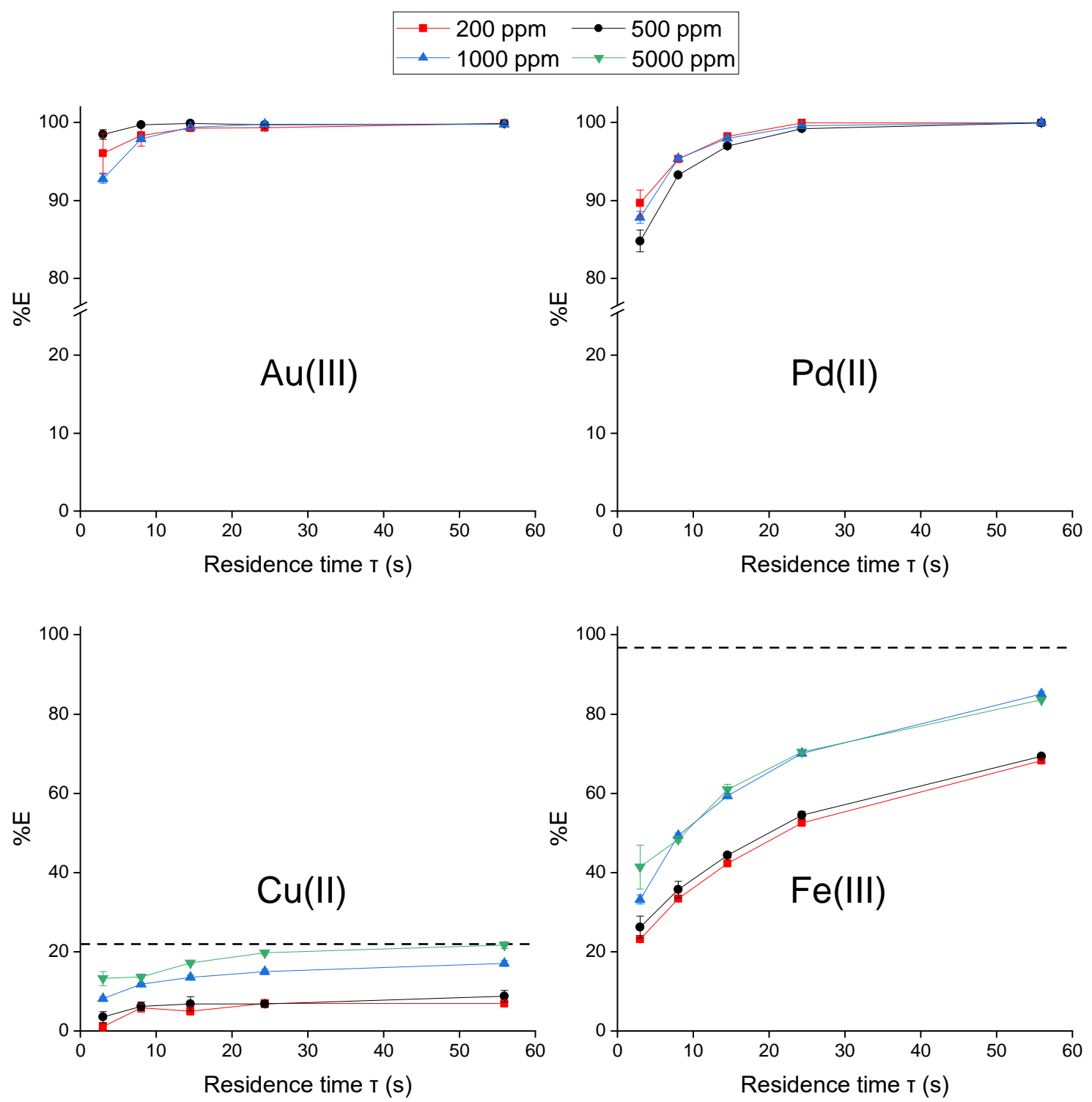

Figure 7: Extraction efficiency of $\mathrm{Au}(\mathrm{III}), \mathrm{Pd}(\mathrm{II}), \mathrm{Cu}(\mathrm{II})$ and $\mathrm{Fe}(\mathrm{III})$ with [A336][Cl] as a function of residence time and metal concentration. Dashed lines represent equilibrium values. Conditions: $0.5 \mathrm{~mol} \mathrm{~L}-1 \mathrm{HCl}$, tube length $20 \mathrm{~cm}, 1.0 \mathrm{~mm} \mathrm{ID,} \mathrm{O/A} \mathrm{1,} \mathrm{total} \mathrm{flow} \mathrm{rate} 140$ $-1500 \mu \mathrm{L} \mathrm{min}{ }^{-1}$, room temperature.

The preceding results on the separation of $\mathrm{Au}(\mathrm{III}), \mathrm{Pd}(\mathrm{II}), \mathrm{Cu}(\mathrm{II})$ and $\mathrm{Fe}(\mathrm{III})$ indicate that enhanced precious/base metal separations can be obtained by performing the extraction process at non-equilibrium conditions using a milliflow contactor. This observation remains valid for most of the studied extraction conditions (i.e. halide concentration, phase ratio or metal concentration) although the magnitude of the obtainable enhancement can change significantly. 
A reduction in the base metal co-extraction infers an advantage to the post-extraction processing of the loaded solvent in terms of scrubbing. Co-extracted $\mathrm{Cu}(\mathrm{II})$ and $\mathrm{Fe}(\mathrm{III})$ can be selectively scrubbed from [A336][Cl] or [A336][Br] through several contacts with water.[53] Reducing their co-extraction through non-equilibrium conditions will result in a reduction of the number of required scrubbing stages and a reduction in water consumption.

\subsection{Flow characteristics}

The stability and uniformity of the obtained slug flow under the various studied conditions is detrimental for a narrow RTD and the reliable operation of a non-equilibrium solvent extraction process. Several works have already discussed the behavior of undiluted ionic liquids in flow applications although the use of undiluted Aliquat 336 in flow has to the best of our knowledge not yet been reported.[32,48,55,68] Hence, high-speed imaging was used to investigate the flow characteristics of the current extraction systems. The results for the bromide extraction system are discussed here, results for the chloride system are provided in the Supporting Information, Figure S7. Because of the intense, dark color of the bromide extraction system upon metal extraction, the internal vortices in the continuous ionic liquid phase can be visualized for some experimental conditions without the need for more complex techniques such as PIV (particle image velocimetry) or LIF (laser-induced fluorescence).[46,48,68] Figure 8a displays highspeed images of the slug flow obtained for the extraction of 500 ppm Au(III), 500 ppm Pd(II), 500 ppm $\mathrm{Cu}(\mathrm{II})$ and $500 \mathrm{ppm} \mathrm{Fe}(\mathrm{III})$ from $2 \mathrm{~mol} \mathrm{~L}^{-1} \mathrm{HBr}$ using [A336][Br] at various flow rates. Characteristic metrics such as ID, plug length $\left(\mathrm{L}_{\mathrm{p}}\right)$, plug height or width $\left(\mathrm{H}_{\mathrm{p}}\right)$ and the unit cell have also been indicated. Using $\mathrm{H}_{\mathrm{p}}$, the film thickness $\mathrm{H}_{\mathrm{f}}$ can be calculated:

$$
\mathrm{H}_{\mathrm{f}}=\frac{\mathrm{ID}-\mathrm{H}_{\mathrm{p}}}{2}
$$


The images show a highly uniform slug flow for all applied flow rates. The plugs have a bulletlike shape, which becomes more pronounced with an increasing flow rate. For the highest flow rate of $1500 \mu \mathrm{L} \mathrm{min}{ }^{-1}$ some irregularities are noticed in the form of a secondary dispersion. This is most likely caused by a shift in the slug formation regime from a squeezing to a dripping or jetting regime.[69,70] As this secondary dispersion has a negative effect on the narrow character of the RTD and the uniformity of the flow, low to moderate flow rates should be preferred for non-equilibrium SX applications with undiluted ionic liquids. For the lower flow rates up to $360 \mu \mathrm{L} \min ^{-1}$ vortices can be identified in the continuous phase due to the discoloration of the organic phase. Figure 8a also shows a clear decrease in $L_{p}$ and an increase in $\mathrm{H}_{\mathrm{f}}$ with flow rate. This is visualized in Figure $8 \mathrm{~b}$ using the dimensionless film thickness and plug length by dividing by the channel radius $\mathrm{R}$ and corresponds well with observations in other literature reports.[32,46,48,68] It must also be noted that the various extraction conditions (i.e. halide concentration) all result in remarkably similar plug dimensions. At 4 mol L-1 $\mathrm{HBr}$, the plugs are the shortest and the film is the most substantial. The small differences can possibly be coupled to a slightly larger ionic liquid viscosity due to a reduced water content at this elevated acid concentration.[64] At the highest flow rates, the film takes up almost $30 \%$ of the channel radius. At this point, the film thickness approaches the limiting value defined by Balestra et al. for the existence of vortices in the continuous phase and consequently also secondary vortices within the plugs.[71] This explains why the visualization of the vortices in Figure $8 \mathrm{a}$ is lost at the elevated flow rates.

High-speed imaging was also used to assess the velocity of the aqueous plugs $U_{p}$, Figure 8c. The presence of the wall film, which can be become quite substantial due to the viscous character of the ionic liquid, results in a significantly higher $U_{p}$ than the average mixture velocity $\mathrm{U}_{\mathrm{mix}}$, which is based on the volumetric throughput. This data and the data in Figure S7c was therefore used for the determination of the actual residence times $\tau$ in the above 
extraction experiments. A discrepancy was also noticed between the applied and the observed phase ratio i.e. an excess of ionic liquid exists in the reaction channel. This can be expressed as the hold-up:

$$
\text { Hold-up }(\%)=\frac{\mathrm{V}_{\mathrm{UC}}-\frac{\mathrm{V}_{\mathrm{p}}}{\mathrm{Q}_{\mathrm{A}} / \mathrm{Q}}}{\mathrm{V}_{\mathrm{UC}}} * 100
$$

with VUc the volume of a unit cell (calculated as the volume of cylinder), $V_{p}$ the volume of a plug (approached as a cylinder with hemispherical caps), $\mathrm{Q}_{\mathrm{A}}$ the applied aqueous volumetric flow rate and $\mathrm{Q}$ the total applied volumetric flow rate. Figure 8c shows that this hold-up approaches $40 \%$ from $1000 \mu \mathrm{L} \mathrm{min}{ }^{-1}$ onwards. This means that a large and rather stagnant ionic liquid film coats the inside of the reaction channel, practically reducing its internal diameter. This in turn increases $U_{p}$, resulting in significantly shorter residence times than anticipated based on the volumetric throughput. A correction of the residence time for this effect is thus important for the correct evaluation of the extraction data.

Figure 8d displays the dimensionless film thickness and plug length as a function of the used phase ratio. $\mathrm{L}_{\mathrm{p}} / \mathrm{R}$ decreases significantly with $\mathrm{O} / \mathrm{A}$ ratio, but approaches a limiting value of 2 from O/A 3/1 onwards. At this limiting value, the characteristic length of the plug becomes equal to that of the channel (i.e. the ID) and the flow regime should be identified as drop flow rather than slug flow. Concurrently with a decrease in length, a slight increase in the film thickness is also observed with an increasing $\mathrm{O} / \mathrm{A}$ ratio.

The specific interfacial area was estimated based on the high-speed imaging. For this, the surface area of a plug was approximated as a cylinder with hemispherical caps and divided by the volume of a unit cell. The results are shown in Table 2 for the bromide extraction system and various extraction conditions, results for the chloride system are provided in the Supplementary Information. The specific interface stays remarkably constant over the entire 
flow rate range with an average value of about $2000 \mathrm{~m}^{2} \mathrm{~m}^{-3}$. These values corresponds well with other literature on slug flow in $1.0 \mathrm{~mm}$ ID channels and are significantly higher than those for more conventional contactors such as stirred vessels or columns (30-500 $\left.\mathrm{m}^{2} \mathrm{~m}^{-3}\right)$.[21] The constant nature of the specific interface suggests that the decreasing plug length and width are compensated by a decreasing unit cell volume. Only for the lowest applied flow rate of $140 \mu \mathrm{L}$ $\min ^{-1}$, a slight increase is noticed. This is in contrast with other reported observations where an increase in specific interfacial area is observed with an increasing flow rate due to the decrease in plug length.[47] The values are also similar for the various halide concentrations, although this is to be expected based on Figure $8 \mathrm{~b}$ and c.

(a)

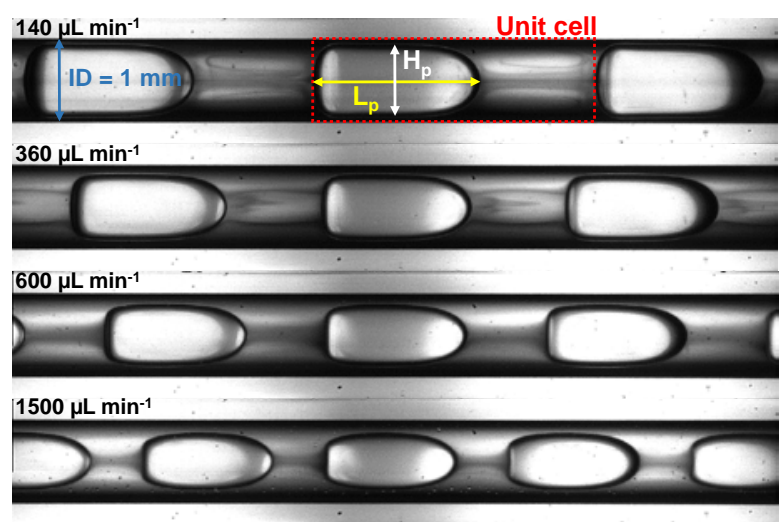

(c)

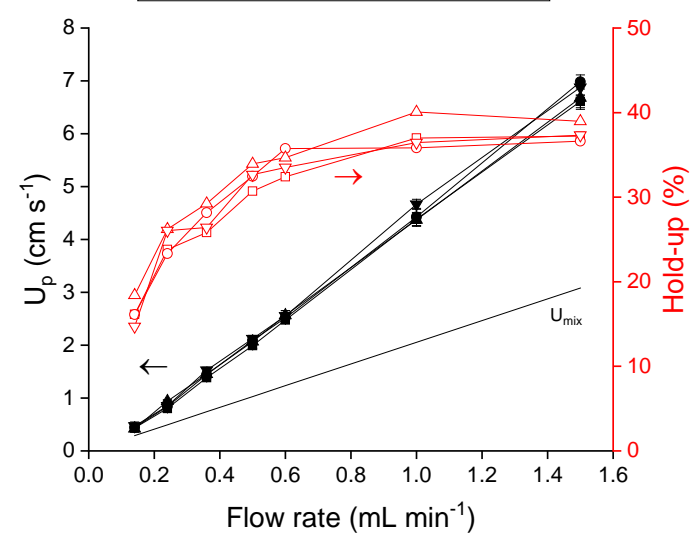

(b)

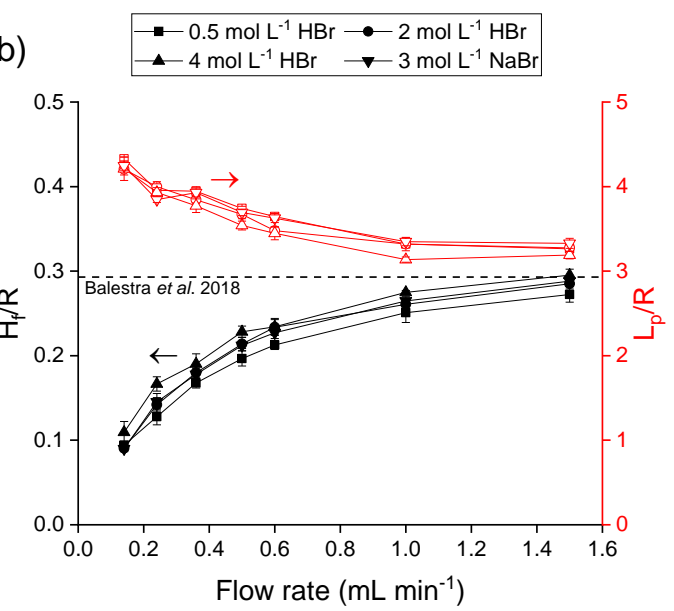

(d)

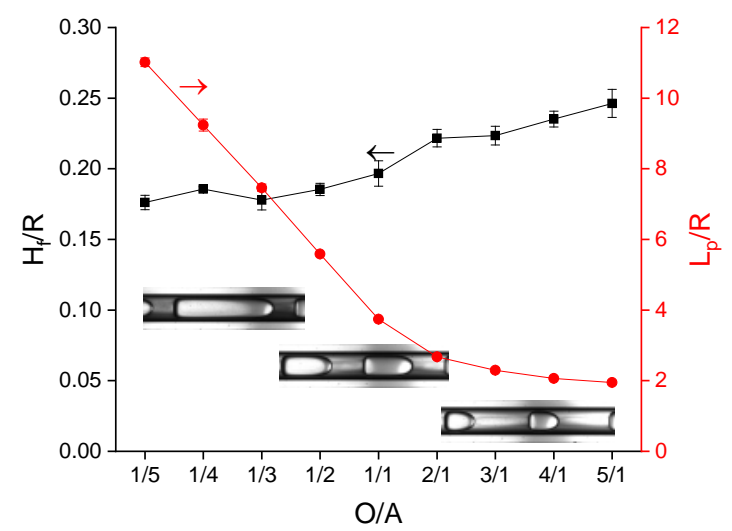

Figure 8: (a) Images of plugs at various flow rates for [A336][Br] and $2 \mathrm{~mol} \mathrm{~L}^{-1} \mathrm{HBr}$; (b) Film thickness and plug length as a function of the applied flow rate for [A336][Br] and various $\mathrm{HBr}$ concentrations; (c) Plug velocity and hold-up as a function of the applied flow rate for [A336][Br] and various $\mathrm{HBr}$ concentrations; (d) Film thickness and plug length as a function of the applied phase ratio for [A336][Br] and $0.5 \mathrm{~mol} \mathrm{~L}^{-1} \mathrm{HBr}$.[71] 
Table 2: Specific interfacial area $\left(\mathrm{m}^{2} \mathrm{~m}^{-3}\right)$ as a function of the total applied volumetric flow rate and extraction conditions for the bromide extraction system. ${ }^{\S}$

\begin{tabular}{ccccc}
\hline \multicolumn{5}{c}{ Total volumetric flow rate $\left(\mathrm{mL} \mathrm{min}^{-1}\right)$} \\
\hline & 0.140 & 0.360 & 0.600 & 1.500 \\
\hline $0.5 \mathrm{~mol} \mathrm{~L}^{-1} \mathrm{HBr}$ & 2118 & 2041 & 1974 & 1995 \\
$2 \mathrm{~mol} \mathrm{~L}^{-1} \mathrm{HBr}$ & 2121 & 2010 & 1935 & 2041 \\
$4 \mathrm{~mol} \mathrm{~L}^{-1} \mathrm{HBr}$ & 2100 & 2007 & 1971 & 1999 \\
$3 \mathrm{~mol} \mathrm{~L}^{-1} \mathrm{NaBr}$ & 2153 & 2048 & 1974 & 2021
\end{tabular}

${ }^{\S}$ Experimental conditions: tube length $20 \mathrm{~cm}, 1.0 \mathrm{~mm}$ ID, O/A 1, total flow rate $140-1500 \mu \mathrm{L}$ $\min ^{-1}$, [A336][Br], room temperature.

\subsection{Improvement of Pt/Pd/Rh separation by non-equilibrium extraction}

Not only precious/base metal separations can be intensified at non-equilibrium conditions, in some cases also precious/precious metal separations may be enhanced. Based on the above discussion on the apparent relationship between the extraction rate and the equilibrium distribution ratio $D$, it was found that a non-equilibrium enhancement of a separation seems to be possible if a significant difference in distribution ratios is present at equilibrium conditions. This is for example the case for the $\mathrm{Pt}(\mathrm{IV}) / \mathrm{Pd}(\mathrm{II}) / \mathrm{Rh}(\mathrm{III})$ separation using [A336][Cl], where $\mathrm{Rh}(\mathrm{III})$ is extracted much less efficiently than $\mathrm{Pt}(\mathrm{IV})$ and $\mathrm{Pd}(\mathrm{II})$.[53] The extraction rate of $\mathrm{Rh}(\mathrm{III})$ can thus be expected to be lower. Figure 9 shows the extraction efficiency of $500 \mathrm{ppm}$ Pt(IV), 500 ppm Pd(II) and 500 ppm Rh(III) using [A336][Cl] as a function of residence time for a $1.0 \mathrm{~mm}$ ID reaction channel. Two different tube lengths $(20$ and $30 \mathrm{~cm})$ and two different $\mathrm{HCl}$ concentrations (1 and $4 \mathrm{~mol} \mathrm{~L}^{-1}$ ) were used. $\mathrm{Pd}(\mathrm{II})$ shows a similar extraction trend 
compared with the previous experiments, reaching 100\% extraction efficiency within approximately 30-40 s. The extraction of Pt(IV) is nearly identical to that of Pd(II), indicating that the above discussion on the precious/base metal separation is most likely equally valid for Pt(IV). Rh(III) extraction indeed proceeds slower and equilibrium values are not reached within the studied time frame indicating that Rh(III) co-extraction can be significantly reduced by working at non-equilibrium conditions. It is also evident from the results shown in Figure 9 that the extraction efficiency of Rh(III) decreases with an increasing chloride concentration. Working at $40 \mathrm{~s}$, complete $\mathrm{Pd}(\mathrm{II})$ and $\mathrm{Pt}(\mathrm{VI})$ recovery is achieved while the $\mathrm{Rh}(\mathrm{III})$ extraction efficiency is reduced from 80 to $60 \%$ at $1 \mathrm{~mol} \mathrm{~L}^{-1} \mathrm{HCl}$. At $4 \mathrm{~mol} \mathrm{~L}-1 \mathrm{HCl}$, Rh(III) extraction is about half its equilibrium value of 33\%. When working at equilibrium conditions, similar separations would require $\mathrm{HCl}$ concentrations of about 3 and $6 \mathrm{~mol} \mathrm{~L}^{-1}$, respectively.[53] Nonequilibrium extractions can thus not only provide advantages in terms of product purity, decontamination or post-extraction processing (i.e. scrubbing or stripping operations) but can also result in a reduced chemical consumption or the use of less corrosive extraction conditions without a reduction in separation performance. 


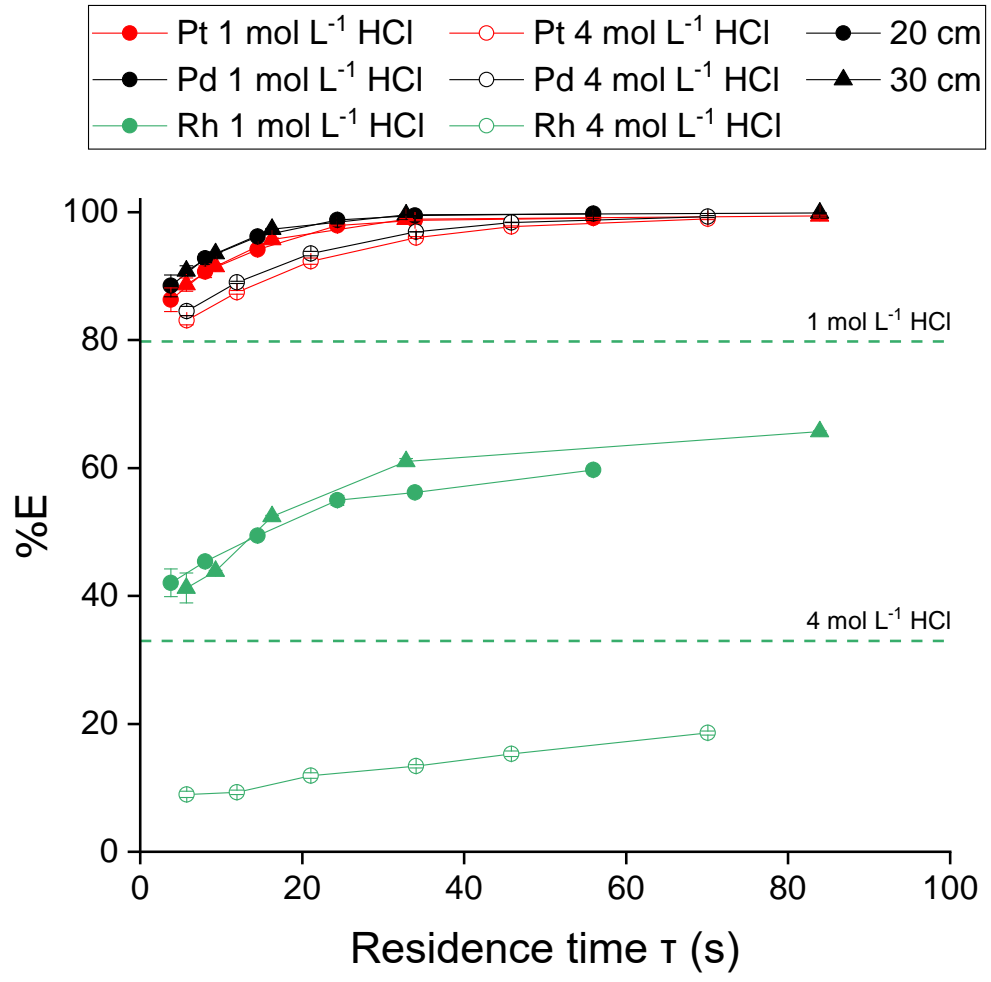

Figure 9: Extraction efficiency of 500 ppm Pt(IV), 500 ppm Pd(II) and 500 ppm Rh(III) with [A336][Cl] as a function of residence time and $\mathrm{HCl}$ concentration. Dashed lines represent equilibrium values. Experimental conditions: 1 and $4 \mathrm{~mol} \mathrm{~L}^{-1} \mathrm{HCl}$, reactor tube length 20 or $30 \mathrm{~cm}, 1.0 \mathrm{~mm} \mathrm{ID,} \mathrm{O/A} \mathrm{1,} \mathrm{total} \mathrm{flow} \mathrm{rate} 140$ - $1200 \mu \mathrm{L} \mathrm{min}{ }^{-1}$, room temperature. 


\section{Conclusion}

Millifluidic devices operating under a slug flow regime have been presented for nonequilibrium solvent extraction processes. Experiments on the separation of $\mathrm{Au}(\mathrm{III}), \mathrm{Pd}(\mathrm{II})$, $\mathrm{Cu}(\mathrm{II})$ and $\mathrm{Fe}(\mathrm{III})$ were performed, using the undiluted quaternary ammonium ionic liquids [A336][Cl] and [A336][Br]. The extraction of $\mathrm{Au}(\mathrm{III})$ and $\mathrm{Pd}(\mathrm{II})$ was found to be significantly faster than the extraction of $\mathrm{Cu}(\mathrm{II})$ and $\mathrm{Fe}(\mathrm{III})$. Based on this difference in extraction rate, an improvement in the precious/base metal separation was possible by working at short contact times. The influence of phase ratio, halide concentration and initial metal concentration on this non-equilibrium enhancement was discussed. An apparent relationship between the observed extraction rate and the equilibrium distribution ratio $D$ was observed. The largest nonequilibrium enhancements were achieved at low halide and metal concentrations and small O/A phase ratios i.e. conditions where the thermodynamic metal separation is best. When quantitative $\mathrm{Au}(\mathrm{III})$ and $\mathrm{Pd}(\mathrm{II})$ recovery is aimed for, decontamination factors can be increased with a factor up to 2 which corresponds to increased product purities of up to $14 \%$. A similar principle was applied to the intensification of the separation of a mixture of $\mathrm{Pt}(\mathrm{IV}), \mathrm{Pd}(\mathrm{II})$ and Rh(III) with undiluted [A336][Cl] based on the slower Rh(III) extraction rate. A hydrodynamic analysis of the obtained ionic liquid slug flow revealed that a highly stable and uniform dispersion could be achieved. A decrease in plug length and width was noticed with increasing flow rates. A significant excess or hold-up of ionic liquid inside the channel was observed, which resulted in the effective channel diameter being reduced and elevated plug velocities. These phenomena must be taken into account for the correct evaluation of the plug residence times. The advantages of millifluidic devices for non-equilibrium solvent extraction include high residence time control, a highly modular set-up, short extraction times (25 - 40 s), increased product purities and a possibility of reduced post-extraction processing (e.g. scrubbing) and reduced consumption of chemicals. 


\section{Supporting Information (SI)}

The Supporting Information includes: the effect of the bromide concentration, phase ratio and initial metal concentration on the $\mathrm{Au}(\mathrm{III}), \mathrm{Pd}(\mathrm{II}), \mathrm{Cu}(\mathrm{II})$ and $\mathrm{Fe}(\mathrm{III})$ separation with undiluted [A336][Br]; the effect of initial metal concentration on $\mathrm{Au}(\mathrm{III}), \mathrm{Pd}(\mathrm{II}), \mathrm{Cu}(\mathrm{II})$ and $\mathrm{Fe}(\mathrm{III})$ separation with undiluted [A336][Cl]; hydrodynamics of the chloride extraction system.

\section{Acknowledgements}

This work was supported by the KU Leuven (project C24/18/042, ISOMER) and FWOFlanders (SB PhD fellowship, 1S47720N).

\section{Conflict of interest}

There are no conflicts to declare. 


\section{References}

[1] A.M. Wilson, P.J. Bailey, P.A. Tasker, J.R. Turkington, R.A. Grant, J.B. Love, Solvent extraction: the coordination chemistry behind extractive metallurgy, Chem. Soc. Rev. 43 (2013) 123-134. https://doi.org/10.1039/C3CS60275C.

[2] J. Rydberg, Solvent Extraction Principles and Practice, Revised and Expanded, CRC Press, New York, 2004.

[3] G.W. Stevens, J.M. Perera, F. Grieser, Metal ion extraction, Curr. Opin. Colloid Interface Sci. 2 (1997) 629-634. https://doi.org/10.1016/S1359-0294(97)80056-8.

[4] S.J. Al-Bazi, A. Chow, Platinum metals-solution chemistry and separation methods (ionexchange and solvent extraction), Talanta. 31 (1984) 815-836. https://doi.org/10.1016/0039-9140(84)80204-0.

[5] P.R. Danesi, R. Chiarizia, C.F. Coleman, The Kinetics of Metal Solvent Extraction, C R C Crit. Rev. Anal. Chem. 10 (1980) 1-126. https://doi.org/10.1080/10408348008542724.

[6] M. Aguilar, J.L. Cortina, Solvent Extraction and Liquid Membranes: Fundamentals and Applications in New Materials, CRC Press, 2008.

[7] K. Wang, C. Niu, D. Qian, J. Liu, X. Chen, D. Lai, Separation of cobalt and nickel by non-equilibrium solvent extraction, J. Cent. South Univ. Technol. 8 (2001) 50-53. https://doi.org/10.1007/s11771-001-0024-5.

[8] K. Mayhew, T. McCoy, D. Jones, K. Barnard, C. Cheng, W. Zhang, D. Robinson, Kinetic Separation of Co from Ni, Mg, Mn, and Ca via Synergistic Solvent Extraction, Solvent Extr. Ion Exch. 29 (2011) 755-781. https://doi.org/10.1080/07366299.2011.595628.

[9] J. Chang, L.B. Zhang, Y. Du, J.H. Peng, G.Y. Hu, J. Chen, C. Srinivasakannan, Separation of indium from iron in a rotating packed bed contactor using Di-2ethylhexylphosphoric acid, Sep. Purif. Technol. 164 (2016) 12-18. https://doi.org/10.1016/j.seppur.2016.03.017.

[10] X. Zhou, J. Zhou, C. Zhang, W. Yu, Application of Annular Centrifugal Contactor on Separating Indium from Iron, Sep. Sci. Technol. 32 (1997) 2705-2713. https://doi.org/10.1080/01496399708006965.

[11] A. Azis, H. Matsuyama, M. Teramoto, Equilibrium and Non-Equilibrium Extraction Separation of Rare Earth Metals in Presence of Diethylenetriaminepentaacetic Acid in Aqueous Phase, J. Chem. Eng. Jpn. 28 (1995) 601-608. https://doi.org/10.1252/jcej.28.601.

[12] H. Matsuyama, A. Azis, M. Fujita, M. Teramoto, Analysis of Extraction Rate and Selectivity of Pr/Nd Separation by Solvent Extraction in the Presence of Diethylenetriaminepentaacetic Acid in Aqueous Phase, J. Chem. Eng. Jpn. 28 (1995) 830-836. https://doi.org/10.1252/jcej.28.830.

[13] Y. Minagawa, Selective extraction of praseodymium ions from neodymium solution using a non-equilibrium extraction method, J. Alloys Compd. 192 (1993) 126-128. https://doi.org/10.1016/0925-8388(93)90207-4.

[14] Y. Minagawa, F. Yajima, Selective Separation of Yttrium Ions from Other Rare Earth Ions Using Nonequilibrium Extraction, Bull. Chem. Soc. Jpn. 65 (1992) 29-33. https://doi.org/10.1246/bcsj.65.29.

[15] W. Duan, T. Sun, J. Wang, Separation of $\mathrm{Nd}^{3+}$ and $\mathrm{Fe}^{3+}$ by non-equilibrium solvent extraction using an annular centrifugal contactor, Sep. Purif. Technol. 146 (2015) 108113. https://doi.org/10.1016/j.seppur.2015.03.044. 
[16] L. Wang, Y. Yu, Y. Liu, Z. Long, Centrifugal extraction of rare earths from wet-process phosphoric acid, Rare Met. 30 (2011) 211-215. https://doi.org/10.1007/s12598-0110370-X.

[17] M. Nakase, Y. Matsuzawa, K. Takeshita, Unique Separation Based on Extraction Kinetics Using a Liquid-liquid Countercurrent Centrifugal Contactor with Taylor Vortices, in: Proc. ISEC2017 - 21st Int. Solvent Extr. Conf., Miyazaki, Japan, 2017.

[18] E.L. Paul, V.A. Atiemo-Obeng, S.M. Kresta, Handbook of Industrial Mixing: Science and Practice, John Wiley \& Sons, 2004.

[19] S. Soboll, L. Bittorf, N. Kockmann, Axial Backmixing and Residence Time Distribution in a Miniaturized, Stirred-Pulsed Extraction Column, Chem. Eng. Technol. 41 (2018) 134-142. https://doi.org/10.1002/ceat.201700152.

[20] M. Nakase, M. Tanaka, K. Takeshita, Continuous Mutual Separation of Lanthanides by a Liquid-liquid Countercurrent Centrifugal Extractor with Taylor Vortices, Energy Procedia. 71 (2015) 106-111. https://doi.org/10.1016/j.egypro.2014.11.860.

[21] M.N. Kashid, A. Renken, L. Kiwi-Minsker, Gas-liquid and liquid-liquid mass transfer in microstructured reactors, Chem. Eng. Sci. 66 (2011) 3876-3897. https://doi.org/10.1016/j.ces.2011.05.015.

[22] S. Dai, J. Luo, J. Li, X. Zhu, Y. Cao, S. Komarneni, Liquid-Liquid Microextraction of Cu2+ from Water Using a New Circle Microchannel Device, Ind. Eng. Chem. Res. 56 (2017) 12717-12725. https://doi.org/10.1021/acs.iecr.7b01888.

[23] M. Darekar, N. Sen, K.K. Singh, S. Mukhopadhyay, K.T. Shenoy, S.K. Ghosh, Liquidliquid extraction in microchannels with Zinc-D2EHPA system, Hydrometallurgy. 144145 (2014) 54-62. https://doi.org/10.1016/j.hydromet.2014.01.010.

[24] E. Kolar, R.P.R. Catthoor, F.H. Kriel, R. Sedev, S. Middlemas, E. Klier, G. Hatch, C. Priest, Microfluidic solvent extraction of rare earth elements from a mixed oxide concentrate leach solution using Cyanex ${ }^{\circledR}$ 572, Chem. Eng. Sci. 148 (2016) 212-218. https://doi.org/10.1016/j.ces.2016.04.009.

[25] M. Yamamoto, S. Taguchi, S. Sato, N. Surugaya, Evaluation of plutonium(IV) extraction rate between nitric acid and tri-n-butylphosphate solution using a glass chip microchannel, J. Sep. Sci. 38 (2015) 1807-1812. https://doi.org/10.1002/jssc.201401315.

[26] L. Zhang, V. Hessel, J. Peng, Liquid-liquid extraction for the separation of Co(II) from $\mathrm{Ni}(\mathrm{II})$ with Cyanex 272 using a pilot scale Re-entrance flow microreactor, Chem. Eng. J. 332 (2018) 131-139. https://doi.org/10.1016/j.cej.2017.09.046.

[27] P. Angeli, D. Tsaoulidis, W. Hashi Weheliye, Studies on mass transfer of europium(III) in micro-channels using a micro Laser Induced Fluorescence technique, Chem. Eng. J. 372 (2019) 1154-1163. https://doi.org/10.1016/j.cej.2019.04.084.

[28] A. Sahu, A.B. Vir, L.N.S. Molleti, S. Ramji, S. Pushpavanam, Comparison of liquidliquid extraction in batch systems and micro-channels, Chem. Eng. Process. Process Intensif. 104 (2016) 190-200. https://doi.org/10.1016/j.cep.2016.03.010.

[29] K. Wang, L. Li, P. Xie, G. Luo, Liquid-liquid microflow reaction engineering, React. Chem. Eng. 2 (2017) 611-627. https://doi.org/10.1039/C7RE00082K.

[30] R. Abiev, S. Svetlov, S. Haase, Hydrodynamics and Mass Transfer of Gas-Liquid and Liquid-Liquid Taylor Flow in Microchannels, Chem. Eng. Technol. 40 (2017) 19851998. https://doi.org/10.1002/ceat.201700041.

[31] P. Angeli, A. Gavriilidis, Hydrodynamics of Taylor flow in small channels: A Review, Proc. Inst. Mech. Eng. Part C J. Mech. Eng. Sci. (2008). https://doi.org/10.1243/09544062JMES776. 
[32] C. Yao, Y. Zhao, G. Chen, Multiphase processes with ionic liquids in microreactors: hydrodynamics, mass transfer and applications, Chem. Eng. Sci. 189 (2018) 340-359. https://doi.org/10.1016/j.ces.2018.06.007.

[33] A. Vansteene, J.-P. Jasmin, G. Cote, C. Mariet, Segmented Microflows as a Tool for Optimization of Mass Transfer in Liquid-Liquid Extraction: Application at the Extraction of Europium(III) by a Malonamide, Ind. Eng. Chem. Res. 57 (2018) 1157211582. https://doi.org/10.1021/acs.iecr.8b02079.

[34] G. Hellé, C. Mariet, G. Cote, Liquid-liquid microflow patterns and mass transfer of radionuclides in the systems Eu(III)/HNO3/DMDBTDMA and U(VI)/HCl/Aliquat ${ }^{\circledR}$ 336, Microfluid. Nanofluidics. 17 (2014) 1113-1128. https://doi.org/10.1007/s10404014-1403-1.

[35] M. Darekar, K.K. Singh, P. Sapkale, A.K. Goswami, S. Mukhopadhyay, K.T. Shenoy, On microfluidic solvent extraction of uranium, Chem. Eng. Process. Process Intensif. 132 (2018) 65-74. https://doi.org/10.1016/j.cep.2018.08.007.

[36] M.E. Leblebici, S. Kuhn, G.D. Stefanidis, T. Van Gerven, Milli-channel mixer and phase separator for solvent extraction of rare earth elements, Chem. Eng. J. 293 (2016) 273-280. https://doi.org/10.1016/j.cej.2016.02.083.

[37] O.K. Castell, C.J. Allender, D.A. Barrow, Liquid-liquid phase separation: characterisation of a novel device capable of separating particle carrying multiphase flows, Lab. Chip. 9 (2009) 388-396. https://doi.org/10.1039/B806946H.

[38] J.G. Kralj, H.R. Sahoo, K.F. Jensen, Integrated continuous microfluidic liquid-liquid extraction, Lab. Chip. 7 (2007) 256-263. https://doi.org/10.1039/B610888A.

[39] F. Scheiff, M. Mendorf, D. Agar, N. Reis, M. Mackley, The separation of immiscible liquid slugs within plastic microchannels using a metallic hydrophilic sidestream, Lab. Chip. 11 (2011) 1022-1029. https://doi.org/10.1039/C0LC00442A.

[40] M. Darekar, R.K. Chaurasiya, K.K. Singh, S. Mukhopadhyay, K.T. Shenoy, In-line phase separator for microfluidic solvent extraction of uranium, J. Radioanal. Nucl. Chem. 324 (2020) 123-133. https://doi.org/10.1007/s10967-020-07052-5.

[41] J. Jovanović, E.V. Rebrov, T.A. Nijhuis, M.T. Kreutzer, V. Hessel, J.C. Schouten, Liquid-Liquid Flow in a Capillary Microreactor: Hydrodynamic Flow Patterns and Extraction Performance, Ind. Eng. Chem. Res. 51 (2012) 1015-1026. https://doi.org/10.1021/ie200715m.

[42] M.N. Kashid, A. Gupta, A. Renken, L. Kiwi-Minsker, Numbering-up and mass transfer studies of liquid-liquid two-phase microstructured reactors, Chem. Eng. J. 158 (2010) 233-240. https://doi.org/10.1016/j.cej.2010.01.020.

[43] S. Yin, K. Chen, C. Srinivasakannan, S. Li, J. Zhou, J. Peng, L. Zhang, Microfluidic solvent extraction of Ce (III) and Pr (III) from a chloride solution using EHEHPA (P507) in a serpentine microreactor, Hydrometallurgy. 175 (2018) 266-272. https://doi.org/10.1016/j.hydromet.2017.12.009.

[44] L. Zhang, V. Hessel, J. Peng, Q. Wang, L. Zhang, Co and Ni extraction and separation in segmented micro-flow using a coiled flow inverter, Chem. Eng. J. 307 (2017) 1-8. https://doi.org/10.1016/j.cej.2016.08.062.

[45] Y. Hirayama, M. Hinoue, H. Tokumoto, A. Matsuoka, K. Noishiki, A. Muto, LiquidLiquid Extraction and Separation of Cobalt and Lithium Ions Using a Slug Flow Microreactor, J. Chem. Eng. Jpn. 51 (2018) 222-228. https://doi.org/10.1252/jcej.17we152.

[46] L. Bai, S. Zhao, Y. Fu, Y. Cheng, Experimental study of mass transfer in water/ionic liquid microdroplet systems using micro-LIF technique, Chem. Eng. J. 298 (2016) 281290. https://doi.org/10.1016/j.cej.2016.04.034. 
[47] D. Tsaoulidis, P. Angeli, Effect of channel size on mass transfer during liquid-liquid plug flow in small scale extractors, Chem. Eng. J. 262 (2015) 785-793. https://doi.org/10.1016/j.cej.2014.10.012.

[48] Q. Li, P. Angeli, Experimental and numerical hydrodynamic studies of ionic liquidaqueous plug flow in small channels, Chem. Eng. J. 328 (2017) 717-736. https://doi.org/10.1016/j.cej.2017.07.037.

[49] T. Welton, Room-Temperature Ionic Liquids. Solvents for Synthesis and Catalysis, Chem. Rev. 99 (1999) 2071-2084. https://doi.org/10.1021/cr980032t.

[50] S. Riaño, K. Binnemans, Extraction and separation of neodymium and dysprosium from used NdFeB magnets: an application of ionic liquids in solvent extraction towards the recycling of magnets, Green Chem. 17 (2015) 2931-2942.

https://doi.org/10.1039/C5GC00230C.

[51] S. Wellens, B. Thijs, K. Binnemans, An environmentally friendlier approach to hydrometallurgy: highly selective separation of cobalt from nickel by solvent extraction with undiluted phosphonium ionic liquids, Green Chem. 14 (2012) 1657-1665. https://doi.org/10.1039/C2GC35246J.

[52] M.L. Firmansyah, F. Kubota, W. Yoshida, M. Goto, Application of a Novel Phosphonium-Based Ionic Liquid to the Separation of Platinum Group Metals from Automobile Catalyst Leach Liquor, Ind. Eng. Chem. Res. 58 (2019) 3845-3852. https://doi.org/10.1021/acs.iecr.8b05848.

[53] W. Vereycken, S. Riaño, T.V. Gerven, K. Binnemans, Extraction Behavior and Separation of Precious and Base Metals from Chloride, Bromide, and Iodide Media Using Undiluted Halide Ionic Liquids, ACS Sustain. Chem. Eng. 8 (2020) 8223-8234. https://doi.org/10.1021/acssuschemeng.0c01181.

[54] T. Vander Hoogerstraete, S. Jamar, S. Wellens, K. Binnemans, Determination of Halide Impurities in Ionic Liquids by Total Reflection X-ray Fluorescence Spectrometry, Anal. Chem. 86 (2014) 3931-3938. https://doi.org/10.1021/ac5000812.

[55] F. Scheiff, A. Holbach, D.W. Agar, Slug Flow of Ionic Liquids in Capillary Microcontactors: Fluid Dynamic Intensification for Solvent Extraction, Chem. Eng. Technol. 36 (2013) 975-984. https://doi.org/10.1002/ceat.201200600.

[56] Y. Wang, I.D. Brindle, Rapid high-performance sample digestion for ICP determination by ColdBlock ${ }^{\mathrm{TM}}$ digestion: part 2: gold determination in geological samples with memory effect elimination, J. Anal. At. Spectrom. 29 (2014) 1904-1911. https://doi.org/10.1039/C4JA00189C.

[57] W. Chen, P. Wee, I.D. Brindle, Elimination of the memory effects of gold, mercury and silver in inductively coupled plasma atomic emission spectroscopy, J. Anal. At. Spectrom. 15 (2000) 409-413. https://doi.org/10.1039/A908658G.

[58] P. Charlesworth, Separating the Platinum Group Metals by Liquid-Liquid Extraction, Platin. Met. Rev. 25 (1981) 106-112.

[59] M.J. Cleare, P. Charlesworth, D.J. Bryson, Solvent extraction in platinum group metal processing, J. Chem. Technol. Biotechnol. 29 (1979) 210-224. https://doi.org/10.1002/jctb.503290403.

[60] F. Crundwell, M. Moats, V. Ramachandran, T. Robinson, W.G. Davenport, Extractive Metallurgy of Nickel, Cobalt and Platinum Group Metals, Elsevier, Amsterdam, 2011.

[61] A. Usher, D.C. McPhail, J. Brugger, A spectrophotometric study of aqueous Au(III) halide-hydroxide complexes at 25-80 C, Geochim. Cosmochim. Acta. 11 (2009) 33593380. https://doi.org/10.1016/j.gca.2009.01.036.

[62] C. Drew Tait, D.R. Janecky, P.S.Z. Rogers, Speciation of aqueous palladium(II) chloride solutions using optical spectroscopies, Geochim. Cosmochim. Acta. 55 (1991) 12531264. https://doi.org/10.1016/0016-7037(91)90304-N. 
[63] I. Persson, Ferric Chloride Complexes in Aqueous Solution: An EXAFS Study, J. Solut. Chem. 47 (2018) 797-805. https://doi.org/10.1007/s10953-018-0756-6.

[64] R. Lommelen, T. Vander Hoogerstraete, B. Onghena, I. Billard, K. Binnemans, Model for Metal Extraction from Chloride Media with Basic Extractants: A Coordination Chemistry Approach, Inorg. Chem. 58 (2019) 12289-12301. https://doi.org/10.1021/acs.inorgchem.9b01782.

[65] W. Liu, B. Etschmann, J. Brugger, L. Spiccia, G. Foran, B. McInnes, UV-Vis spectrophotometric and XAFS studies of ferric chloride complexes in hyper-saline $\mathrm{LiCl}$ solutions at $25-90^{\circ} \mathrm{C}$, Chem. Geol. 231 (2006) 326-349. https://doi.org/10.1016/j.chemgeo.2006.02.005.

[66] M.N. Kashid, A. Renken, L. Kiwi-Minsker, Influence of Flow Regime on Mass Transfer in Different Types of Microchannels, Ind. Eng. Chem. Res. 50 (2011) 6906-6914. https://doi.org/10.1021/ie102200j.

[67] D. Tsaoulidis, V. Dore, P. Angeli, N.V. Plechkova, K.R. Seddon, Dioxouranium(VI) extraction in microchannels using ionic liquids, Chem. Eng. J. 227 (2013) 151-157. https://doi.org/10.1016/j.cej.2012.08.064.

[68] V. Dore, D. Tsaoulidis, P. Angeli, Mixing patterns in water plugs during water/ionic liquid segmented flow in microchannels, Chem. Eng. Sci. 80 (2012) 334-341. https://doi.org/10.1016/j.ces.2012.06.030.

[69] J.D. Tice, A.D. Lyon, R.F. Ismagilov, Effects of viscosity on droplet formation and mixing in microfluidic channels, Anal. Chim. Acta. 507 (2004) 73-77. https://doi.org/10.1016/j.aca.2003.11.024.

[70] L. Bai, Y. Fu, S. Zhao, Y. Cheng, Droplet formation in a microfluidic T-junction involving highly viscous fluid systems, Chem. Eng. Sci. 145 (2016) 141-148. https://doi.org/10.1016/j.ces.2016.02.013.

[71] G. Balestra, L. Zhu, F. Gallaire, Viscous Taylor droplets in axisymmetric and planar tubes: from Bretherton's theory to empirical models, Microfluid. Nanofluidics. 22 (2018) 67. https://doi.org/10.1007/s10404-018-2084-y. 